\title{
Battery Technology Life Verification Test Manual Revision 1
}

December 2012

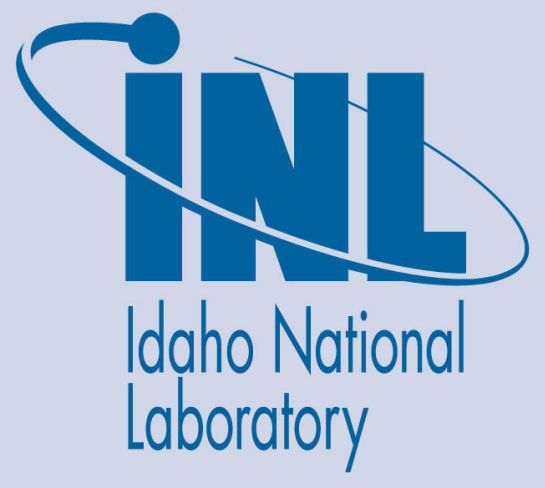

The INL is a U.S. Department of Energy National Laboratory operated by Battelle Energy Alliance 
INL/EXT-12-27920

\title{
Battery Technology Life Verification Test Manual Revision 1
}

December 2012

\author{
Idaho National Laboratory \\ Idaho Falls, Idaho 83415
}

http://www.inl.gov

Prepared for the

U.S. Department of Energy

Assistant Secretary for Energy Efficiency and Renewable Energy

Under DOE Idaho Operations Office

Contract DE-AC07-05ID14517 
Disclaimer

This report was prepared as an account of work sponsored by an agency of the United States

Government. Neither the United States Government nor any agency thereof, nor any of their employees, makes any warranty, express or implied, or assumes any legal liability or responsibility for the accuracy, completeness, or usefulness of any information, apparatus, product, or process disclosed, or represents that its use would not infringe privately owned rights. References herein to any specific commercial product, process, or service by trade name, trademark, manufacturer, or otherwise does not necessarily constitute or imply its endorsement, recommendation, or favoring by the United States Government or any agency thereof. The views and opinions of authors expressed herein do not necessarily state or reflect those of the United States Government or any agency thereof. 


\section{FORWARD}

This Battery Technology Life Verification Test Manual was prepared for the United States Department of Energy (DOE), Office of Energy Efficiency and Renewable Energy (EERE), Vehicle Technologies Program. It is intended to assist developers in successfully designing test matrices for statistically relevant life estimations of energy storage devices for electric, hybrid-electric, or plug-in hybrid electric vehicle applications. The original publication of this Battery Technology Life Verification Test Manual included modifications to the standard DOE test manual procedures as well as a high-level discussion of life modeling tools and approaches. In Revision 1, the matrix designs and performance test procedures were made more compatible with the existing DOE test manuals. Life modeling tools and approaches are now published in a companion manual (Battery Life Estimator Manual, Revision 1, INL-EXT-08-15146, October 2012).

The DOE-United States Advanced Battery Consortium, Electrochemical Energy Storage Technical Advisory Committee supported the development of this manual. Technical team point of contacts responsible for its development and revision are Jon P. Christophersen of Idaho National Laboratory (INL), Ira Bloom of Argonne National Laboratory (ANL), Edward Thomas of Sandia National Laboratories (SNL), and Vincent Battaglia of Lawrence Berkeley National Laboratory (LBNL). The authors also gratefully acknowledge the significant contributions to the original version of this manual from Harold Haskins (retired, USABC) and Gary Hunt (retired, INL).

The development of this manual was funded by the United States Department of Energy, Office of Energy Efficiency and Renewable Energy, Vehicle Technologies Program. Technical direction from DOE was provided by David Howell, Energy Storage R\&D Manager and Hybrid Electric Systems Team Leader, and Brian Cunningham, Energy Storage Testing, Design, and Analysis Program Manager.

Comments and questions regarding this manual should be directed to Jon P. Christophersen at the Idaho National Laboratory (jon.christophersen@inl.gov). 


\section{CONTENTS}

GLOSSARY OF TERMS

1. INTRODUCTION

1

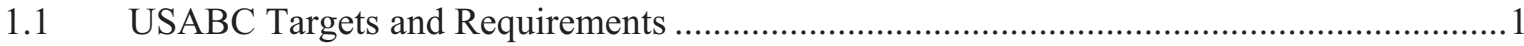

1.2 Battery Technology Life Verification Objectives ...........................................................

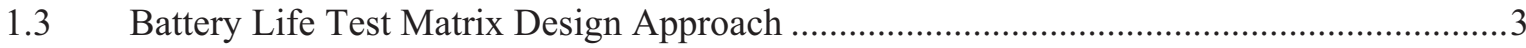

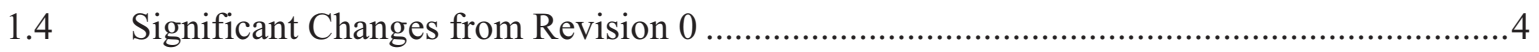



2. LIFE TEST EXPERIMENT DESIGN REQUIREMENTS …..................................................

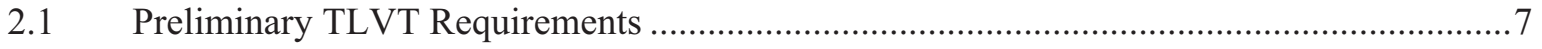

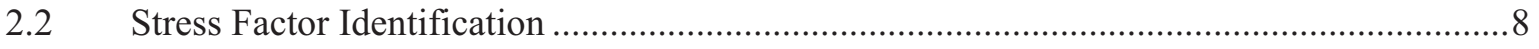

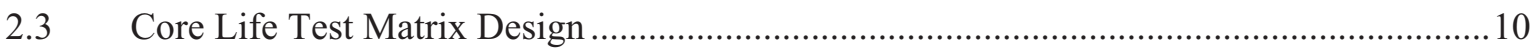

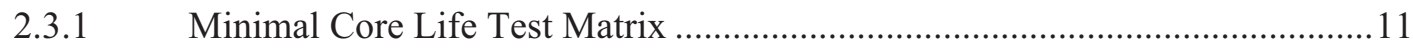

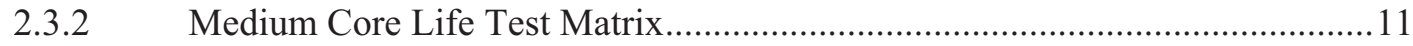

2.3.3 Full Factorial Core Life Test Matrix …............................................................ 14

$2.4 \quad$ Core Life Test Matrix Verification ...................................................................................

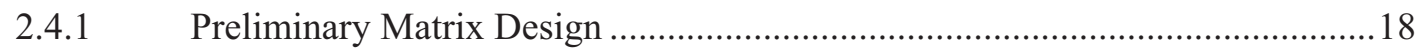

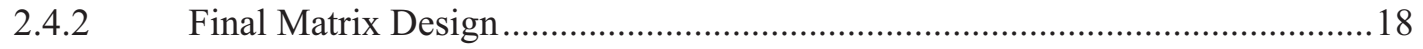

2.4.3 Verification Testing .............................................................................. 19

2.5 Supplemental Life Test Matrix Design Requirements................................................... 19

2.5.1 Experimental Plan to Assess Path Dependence ...............................................20

2.5.2 Experimental Plan to Assess Cold-Start Operation .........................................21

2.5.3 Experimental Plan to Assess Low-Temperature Operation................................22

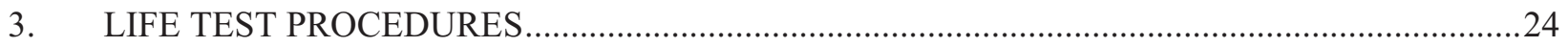

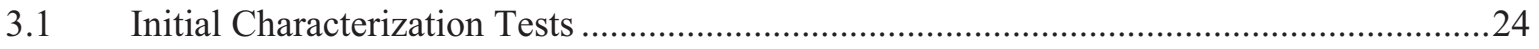

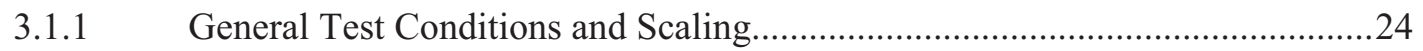

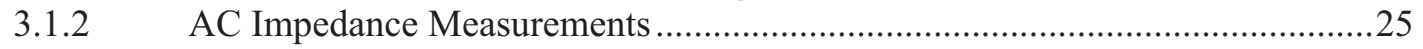

3.1.3 Minimum Characterization Testing .........................................................25 


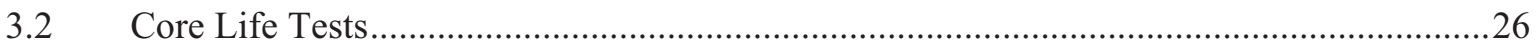

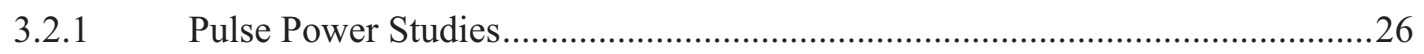

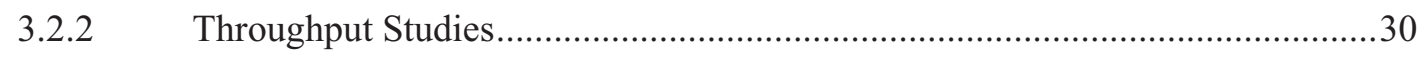

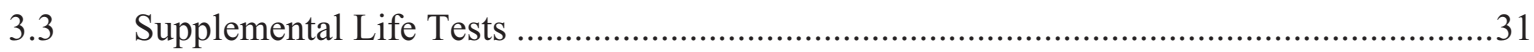

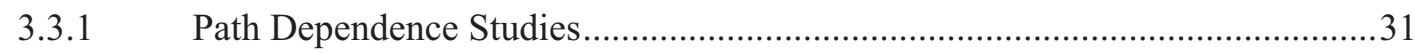

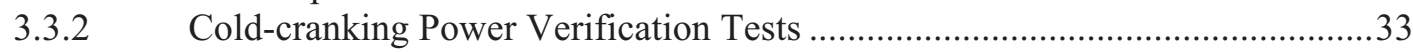

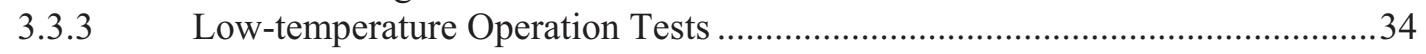

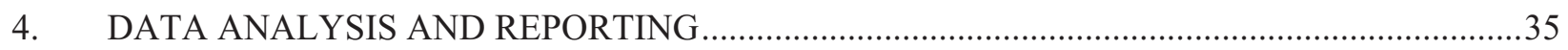

4.1 Initial Performance Characterization Test Results...........................................................35

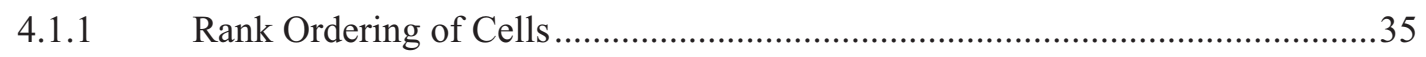

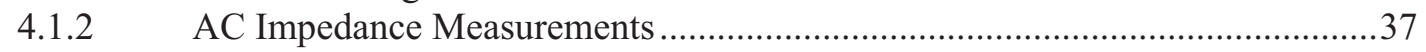

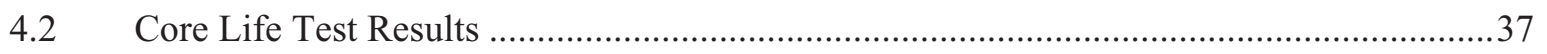

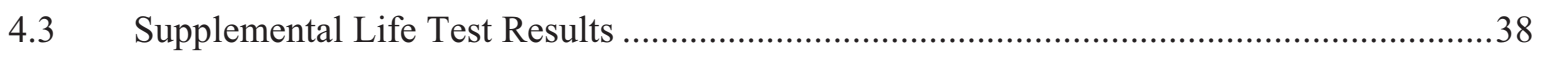



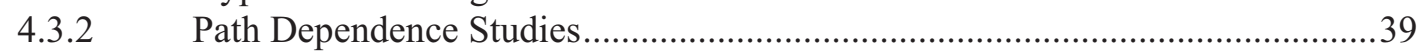

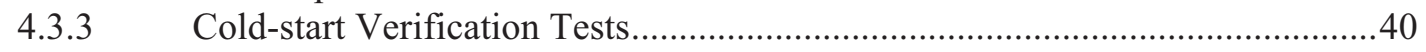

4.3.4 Low-temperature Operation Tests .............................................................. 41

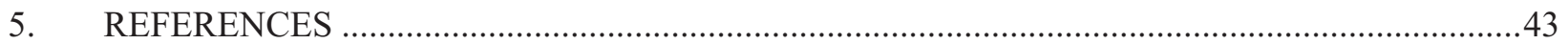




\section{FIGURES}

Figure 1. Adjusted $25 \mathrm{Wh}$ power-assist Baseline cycle life test profiles (discharge) ............................28

Figure 2. Adjusted $25 \mathrm{Wh}$ power-assist Baseline cycle life test profiles (charge) ................................29

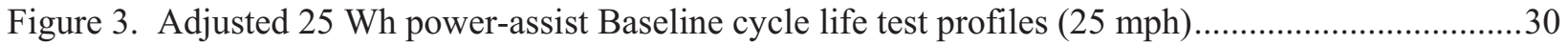

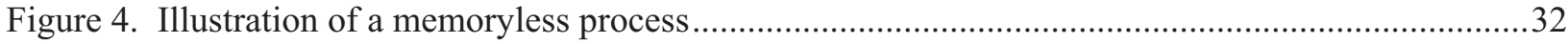

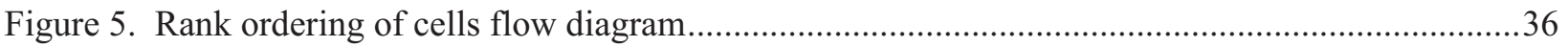

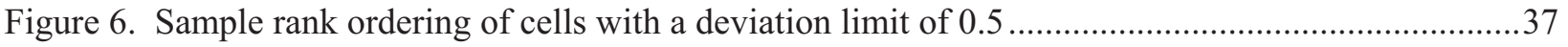

Figure 7. Expected ASI histories for combined cycle/calendar and calendar/cycle test conditions...........39 


\section{TABLES}

Table 2.1. Basic stress factors and suggested stress levels for accelerated life testing. ...........................9

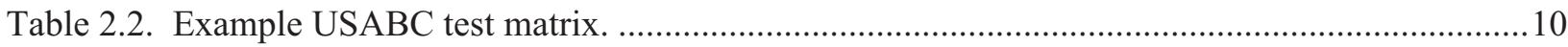

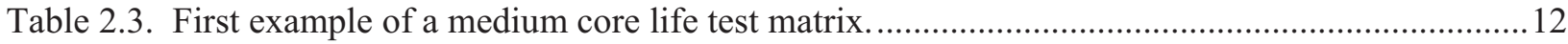

Table 2.4. Second example of a medium core life test matrix; cycle-life emphasis. ...............................13

Table 2.5. Suggested calendar life matrix design........................................................................... 15

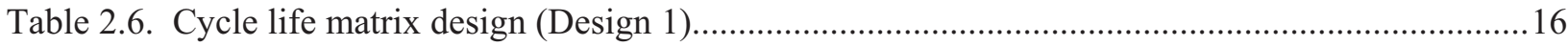

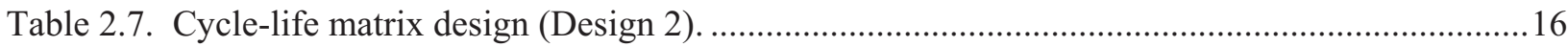

Table 2.8. Example of a path dependence supplemental life test matrix. ..............................................21

Table 2.9. Example of a cold-start supplemental life test matrix. ..........................................................22

Table 2.10. Example of a low-temperature supplemental life test matrix.............................................23

Table 3.1. Baseline 25-Wh cycle life test profile (Reference 4). ....................................................27

Table 3.2. Adjusted Baseline 25-Wh cycle life test profile ( $80 \%$ discharge power)

Table 3.3. Adjusted Baseline 25-Wh cycle life test profile (96\% discharge power)...............................27

Table 3.4. Adjusted Baseline 25-Wh cycle life test profile ( $80 \%$ regen power)...................................29

Table 3.5. Adjusted Baseline 25-Wh cycle life test profile (95\% regen power)....................................29

Table 3.6. Adjusted Baseline 25-Wh cycle life test profile $(25 \mathrm{mph})$...................................................... 31 


\section{GLOSSARY OF TERMS}

Acceleration rate - Ratio of calendar life to life on test.

Area-Specific Impedance (ASI) - The impedance of a device relative to the electrode area of the device, defined as the change in cell voltage $(V)$ as a result of a change in cell current divided by the change in cell current (A), all multiplied by the active superficial cell area $\left(\mathrm{cm}^{2}\right), \mathrm{ohm}-\mathrm{cm}^{2}$.

Beginning of Life (BOL) - The point in time at which life testing begins. A distinction is made in this manual between the performance of a battery at this point and its initial performance, because some degradation may take place during early testing before the start of life testing. Analysis of the effects of life testing is based on changes from the BOL performance.

$C_{1} / 1$ Rate - The rate corresponding to completely discharging a fully charged device in exactly one hour. Otherwise, a rate corresponding to the manufacturer's rated capacity (in ampere-hours) for a one-hour constant current discharge. For example, if the battery's rated one-hour capacity is $1 \mathrm{Ah}$, then the $\mathrm{C}_{1} / 1$ constant current rate is $1 \mathrm{~A}$. The $\mathrm{C}_{1} / 1$ rate is the reference discharge rate for power-assist applications; other applications may have different reference rates, $\mathrm{hr}^{-1}$.

Calendar Life - The time required to reach end of life at the reference temperature at open-circuit (corresponding to key-off/standby conditions in the vehicle).

Cycle Life - The number of consecutive cycles consisting of a charge neutral combination of discharge and charge pulses centered on a given state-of-charge for Hybrid Electric Vehicles (HEVs) or between given voltage limits for Plug-in Electric Vehicles and Electric Vehicles (PHEVs and EVs) required to reach end of life at the reference temperature.

Degradation Model - An empirical- or chemistry/physics-based model that describes the expected degradation of a battery experiencing typical stress conditions.

End of Life (EOL) - A condition reached when the device under test is no longer capable of meeting the applicable USABC goals. This is normally determined from RPT results, and it may not coincide exactly with the ability to perform the life test profile (especially if cycling is done at elevated temperatures.) The number of test profiles executed at end of test is not necessarily equal to the cycle life per the USABC goals.

End of Test (EOT) - The point in time where life testing is halted, either because criteria specified in the test plan are reached, or because it is not possible to continue testing. 
Error Model - A model that accounts for the difference between the measured and expected performance. The error model combines the effects of both measurement error and manufacturing variability.

Life in service - The time required to reach end of life at the nominal conditions of normal usage in the vehicle (e.g., $30^{\circ} \mathrm{C}$ and specified cycling conditions).

Life on test - The time required to reach end of life at the test conditions specified for accelerated life testing.

Memoryless Degradation - A process wherein the degradation rate of a cell depends only on its present state and present stress levels.

Reference Performance Test (RPT) - A periodic assessment of battery degradation during life testing. A reference performance test will typically yield capacity fade, power fade, and impedance rise as a function of test time.

State of Charge (SOC) - The available capacity in a battery expressed as a percentage of actual capacity. This is normally referenced to a constant current discharge at the $\mathrm{C}_{1} / 1$ rate. For this manual, it may also be determined by a voltage obtained via a relationship of capacity to voltage established at beginning of life. SOC $=(100-$ DOD) if the rated capacity is equal to the actual capacity, $\%$.

State of Health $(\mathrm{SOH})$ - The present fraction of allowable performance deterioration remaining before EOL. ( $\mathrm{SOH}=100 \%$ at beginning of life and $0 \%$ at end of life.)

Stress Factors - The parameters that are used to accelerate aging of a battery technology, such as temperature, state-of-charge, throughput, and pulse power. These are the explanatory variables in the degradation model. 


\section{ACRONYMS}

ABR Applied Battery Research

AC alternating current

ANL Argonne National Laboratory

ANOVA analysis of variance

ASI area-specific impedance

BLE Battery Life Estimator

BOL beginning of life

BSF battery size factor

DOE Department of Energy

EERE Energy Efficiency and Renewable Energy

EOL end of life

EOT end of test

ESR equivalent series resistance

EV electric vehicle

HEV hybrid electric vehicle

INL Idaho National Laboratory

LBNL Lawrence Berkeley National Laboratory

MPPC Minimum Pulse Power Characterization (test)

OEM original equipment manufacturer

P-CLEM Power-based Cycle Life Efficiency Model

PHEV plug-in hybrid electric vehicle

RPT reference performance test

SNL Sandia National Laboratories

SOC state of charge

$\mathrm{SOH} \quad$ state of health

TLVT Technology Life Verification Testing

USABC United States Advanced Battery Consortium 


\section{Battery Technology Life Verification Test Manual}

\section{INTRODUCTION}

The purpose of this Technology Life Verification Test (TLVT) Manual is to help guide developers in their effort to successfully commercialize advanced energy storage devices such as battery and ultracapacitor technologies. The experimental design and data analysis discussed herein are focused on automotive applications based on the United States Advanced Battery Consortium (USABC) electric vehicle, hybrid electric vehicle, and plug-in hybrid electric vehicle (EV, HEV, and PHEV, respectively) performance targets. However, the methodology can be equally applied to other applications as well. This manual supersedes the February 2005 version of the TLVT Manual (Reference 1). It includes criteria for statistically-based life test matrix designs as well as requirements for test data analysis and reporting. Calendar life modeling and estimation techniques, including a user's guide to the corresponding software tool is now provided in the Battery Life Estimator (BLE) Manual (Reference 2).

This section introduces the USABC performance targets and life verification objectives, along with the general approaches for life test matrix design, reference performance testing, and life test data analysis. A summary of the significant changes from the original version of this manual (Reference 1) is then provided, followed by a brief discussion on the organization of the manual.

\subsection{USABC Targets and Requirements}

The USABC life testing targets and requirements are assumed to be based on the standardized methodologies developed under the Department of Energy's (DOE's) Vehicle Technologies Program. To date, these test procedures primarily include the plug-in hybrid-electric vehicle (Reference 3), power-assist hybrid-electric vehicle (Reference 4), electric vehicle (Reference 5), and ultracapacitor (Reference 6) test manuals. Other testing requirements and procedures could also be implemented as necessary. It is further assumed that most technologies at the TLVT stage will be at the cell level. Appropriate scaling of cell-level performance parameters for comparisons with the targets will be based on the test manual requirements (References 3 through 6) or specified by the manufacturer. Battery modules or packs may also be used for technology life prognostics if needed, but at additional costs.

\subsection{Battery Technology Life Verification Objectives}

Commercialization and implementation of advanced batteries for automotive applications generally requires battery life capability assessment in four distinct stages. The first stage is addressed in the standardized battery test manuals (References 3 through 6), where 
cells are characterized and aged using standardized test procedures. Test matrices will typically consist of a small number of cells at three or four different temperatures and one or two states-of-charge (SOCs). The primary objective at this stage is to verify that the battery is capable of meeting the performance targets over a 15-year, 150,000-mile life. Test data from these studies are also instrumental in developing appropriate empirical, semi-empirical, or physics-based models for successful life prediction.

The second stage, addressed in this manual, is meant to demonstrate the battery technology's readiness for transition to production. Test articles will generally be prototypical battery cells with a mature, well-characterized chemistry. The primary objective at this stage is to verify that the cell-level performance model is accurate and the average life capability is estimated at a high statistical confidence level. An important secondary objective is to provide data for optimization of the battery product design and usage. These objectives need to be met with minimum cost and time expended for life testing. This implies careful use of accelerated life testing at elevated levels of key stress factors. Prerequisites for this second stage of battery technology life verification testing are as follows:

- Life-limiting wearout mechanisms must be identified and characterized (e.g., with standardized performance testing during Stage 1).

- A life model (empirical, semi-empirical, or physics-based) that accurately reflects typical degradation over time as a function of the indentified life-limiting wearout mechanisms.

- An error model that accounts for both measurement uncertainty and manufacturing variability.

- Sufficient supply of cells, test channels, and temperature chambers for core and supplemental aging experiments.

The third stage of life verification is an integral part of product design verification that is conducted jointly by a production battery supplier and an automotive original equipment manufacturer (OEM). The objectives at this stage are to (1) demonstrate that the complete battery system meets the life target for its intended usage by the $90^{\text {th }}$ percentile customer, and (2) help with the development of product warranty policy and projected warranty costs. Multiple cells and/or full battery pack systems from production lots will generally be required to establish true performance capability and accurate life estimations. Detailed requirements for life verification are subject to OEM/supplier negotiation, under timing and budget constraints for vehicle development. Prerequisites for this third stage of battery technology life verification testing are as follows:

- The development status of a candidate technology must be such that its key materials and fabrication processes are stable and completely traceable.

- A high percentage of cells produced must represent the "best" of the technology. 
- Life-limiting wearout mechanisms must be identified and characterized by physical diagnostic tools.

- Accurate battery life models and error models that have been validated are available.

- Parallel evaluation of alternative cell designs, materials, and fabrication processes should be completed.

- Detailed cell production planning should be in progress.

The fourth stage involves onboard assessment of battery state-of-health and remaining useful life while in operation. At this stage, online sensors are required to capture relevant measurements (e.g., voltage, current, temperature, etc.) that can be used in combination with modeling tools to assess the overall battery condition. The sensor data and online interpretation could be implemented through a battery management system that provides feedback to the overall system for improved power management and control. Simple passive measurements of voltage and current can be used to estimate the capacity and state-of-charge through various techniques such as coulomb counting and look-up tables. Active measurements such as AC impedance spectra could be used in combination with feature extraction to provide parameter estimations for fundamental modeling tools that can more accurately assess, predict and manage battery life capability (References 7-8).

\subsection{Battery Life Test Matrix Design Approach}

Successful battery technology life verification testing must include a range of stress factors appropriate to achieving high, but relevant, acceleration rates. The goal is to verify (with a high level of statistical confidence) that the battery life is at least 15 years within only one to two years of accelerated aging. To be relevant, an elevated stress factor must induce a wearout failure mode that truly represents the failure modes that will occur in normal service. Selection of specific stress factors and levels must be based on a thorough understanding of the relevant wearout modes for the candidate technology. Significant stress factors that should be considered are temperature and SOC, though other stressors such as rate of energy throughput and variations on pulse power levels could be considered as well. Although test efficiency is desired, the life test matrix should also reflect known or suspected interactions between stress factors. Confounding of effects for critical stress factor interactions must be avoided.

Two fundamental test matrices are defined in this manual: the core life matrix and supplemental life matrix. The core life test matrix addresses the life estimation requirements by allocating cells to various stress conditions at relevant acceleration rates. These data are used to validate the life model and verify the assumed levels of manufacturing variability and measurement error. A simulation tool has been developed to support the optimization of the core life test matrix. This Battery Life Estimator tool 
(Reference 2) uses a Monte Carlo approach to simulate a life testing regime for a given set of cells, wherein the true response of the simulated cells (i.e., based on the degradation model) is corrupted with specified noise levels induced by test measurement errors and cell-to-cell manufacturing variability. Numerous trials are simulated, each corresponding to a replication of the life test at the specified acceleration rates. Each Monte Carlo trial results in simulated cell performance deterioration from which the life capability can be estimated. The variation in estimated life capability across the set of trials provides a basis for developing confidence limits. The target is to meet the 15 -year, 150,000-mile life at a minimum of $90 \%$ confidence level, though other confidence levels can be used as well. Assuming that the simulations accurately reflect the true cell performance and testing, the actual life test should yield, with $90 \%$ probability, a projected life that is compared to the 15-year target. The life test simulation tool can be used to optimize matrix design variables such as the number of cell replicates at each stress level and the frequency of reference performance tests (RPTs), given the test measurement and manufacturing noise levels. If the assumed measurement and manufacturing noise levels do not match the values determined from the actual core-life test matrix, then the test matrix may need to be modified, for example by increasing the number of replicate cells at some of the critical stress conditions, and the simulation trials repeated.

The second fundamental matrix defined in this manual is for supplemental life testing that addresses various off-normal conditions that are assumed to have little to no impact on life estimations. These conditions can include, but are not limited to, periodic cold cranking, low-temperature operation within specified regenerative pulse current limits, and path dependence or memory effects. Path dependence examples can include sequential combinations of calendar life (non-operating) and cycle life (pulse-mode operation), thermal swings, SOC swings, or any combinations thereof.

\subsection{Significant Changes from Revision 0}

Validation testing based on the original version of this manual (Reference 1) resulted in several modifications to both the testing requirements and life estimation tools. First, the testing protocols were made more synergistic with the standardized procedures developed under the DOE Vehicle Technologies Program (References 3 through 6). For example, the original manual specified a new RPT using the Minimum Pulse Power Characterization (MPPC) test that was designed to minimize impact on cell life while providing sufficient information to predict remaining useful life. However, the validation testing effort identified issues with the MPPC resistance data (Reference 9) and its effect on life estimations compared to standardized USABC testing performed under Stage 1. Additionally, the testing requirements for Stage 2 applications should be similar to those under Stage 1 so the model can be appropriately validated (see Section 3).

Second, additional TLVT matrix designs were developed to accommodate resource limitations. The original manual (Reference 1) required hundreds of cells under multiple conditions for accurate life predictions. While this is still desirable, it is also recognized 
that the number of available cells, temperature chambers, test channels, etc. are limited. This manual now provides three different core life test matrix sizes to accommodate available resources (see Section 2.3).

Third, the life modeling approach and software tools have been improved and are now discussed in greater detail in the Battery Life Estimator Manual (Reference 2). Although a manufacturer-specific model is more desirable, generalized semi-empirical degradation models have been developed for both linearizable and nonlinear fits. Additionally, an error model with lack-of-fit statistic has been developed with an improved methodology to determine measurement uncertainty.

\subsection{Organization of the Manual}

This manual is organized into the following major sections. Section 2 contains requirements for the life test experiment, including (a) characterization of battery failure modes, (b) selection of stress factors and stress levels, (c) design and verification of the core life test matrix, and (d) design of a supplemental life test matrix. Section 3 contains guidelines and suggested test profiles for both the core and supplemental matrices. Section 4 contains requirements for test data analysis and reporting, including the initial characterization and allocation of batteries to the core and supplemental matrices, and the

analysis of the supplemental life test matrix data, including identification of any additional stress factors, beyond those included in the core matrix, that significantly effect battery life. Section 5 provides a list of references. 


\section{LIFE TEST EXPERIMENT DESIGN REQUIREMENTS}

This section presents the general requirements for planning and designing a battery technology life verification test experiment. Since this manual is intended to augment previous Stage 1 testing (see above), it is assumed that the candidate technology will have already been subjected to characterization and life testing using standardized matrices. Consequently, the performance degradation mechanisms, principal life-limiting stresses, maximum allowable stress levels to avoid irrelevant degradation mechanisms, and the general time-dependence of the performance degradation should already reasonably well known. Given these prerequisites, different life test experimental designs are provided in this section to yield estimates of mean cell life.

Once the candidate technology has been appropriately characterized under Stage 1 testing, several decisions are to be made in the final design of the Stage 2 life test experiment. The test facilities, total duration of the life testing, and frequency of performance measurement are specified first. The total number of cells to be tested and allocation of the cells to the various stress conditions are then key considerations that strongly depend on (a) the desired confidence in the test results for projected life in service, (b) the expected cell-to-cell performance variation, and (c) the performance measurement capabilities of the test facilities. The experimental design objective is to allocate cells to each test condition, such that testing resources (i.e., the total number of cells) are minimized for a specified level of confidence (e.g., 90\%).

A life test simulation tool, as described in the Battery Life Estimator Manual (Reference 2 ), supports the experimental design process. This tool can be used to maximize confidence in the final projection of life in service from the obtained simulated test data within the practical constraints on the scope of the test program. The simulation uses Monte Carlo techniques and includes generalized semi-empirical degradation models and an error model that accounts for measurement uncertainty and manufacturing variability. The full simulation can also be used to iteratively adjust and verify the final allocation of cells in the matrix prior to actual Stage 2 testing. Later, at the start of actual testing, the simulation can be used to reverify the experiment design and assumed noise levels using initial characterization data from the actual test cells. Note that this simulation tool is also useful during Stage 1 testing to help develop a degradation model and yield preliminary estimates of life capability for candidate cell technologies.

A complete life test experiment also includes a supplemental life test matrix to verify that special operating conditions such as periodic cold-cranking and low-temperature operation do not adversely affect battery life. This verification can be done by comparing the results between the core matrix of test conditions and the supplemental test conditions, preferably using cells from the same lot number. Cells from different lot numbers could be used if the manufacturing variability is low enough, otherwise portions of the core matrix may need to be re-tested for best comparisons with the supplemental life test results.

Requirements for design of the life test experiment, based on this general process, are provided in the following. Section 2.1 discusses the preliminary requirements for 
candidate technologies prior to detailed life verification test planning. Section 2.2 provides guidelines for selecting the significant stress factors for the core matrix. Section 2.3 provides general guidelines for the development of the core matrix, and provides numerous examples of matrix designs based on assumed constraints. Section 2.4 describes how the Monte Carlo simulation tool is used to finalize the preliminary cell allocations and to reverify the overall experiment design using initial cell characterization data. Section 2.5 specifies the requirements for the supplemental life test matrix.

\subsection{Preliminary TLVT Requirements}

For accurate battery life estimations, it is necessary first to identify the wearout mechanisms responsible for loss of performance and limited life capability (e.g., capacity fade, resistance rise, and power fade) using standardized testing procedures and requirements during Stage 1 testing. As stress levels are increased, the physical mechanisms may change from those applicable under normal usage to ones that are irrelevant. Consequently, it is also necessary to determine limiting values of the stress factors to be used in the life test, such that abnormally high rates of degradation are avoided. If not, the influence of a given stress factor may be overestimated at high values of the life test acceleration rate. This could result in overestimation of the projected life in service.

Once identified, these stress factors must be integrated into a life model that can, with calibration, support quantitative investigations of how candidate stress factors affect rates of performance degradation. Ideally, a phenomenological model will be available, but an empirical or semi-empirical model based on performance data from Stage 1 testing could be used as well. In conjunction with this life model, an error model is also required to account for the cell-to-cell variability induced by the manufacturing and the measurement uncertainty due to the testing activity. Ideally, this variability is small enough that the number of batteries required to verify life capability is kept to a manageable level. Manufacturers are encouraged to develop their own models that best describe their particular chemistries.

The next step in planning the life verification experiment would be using the Battery Life Estimator software tool (Reference 2) to incorporate the technology-specific life model or the default model (linearizable or nonlinear form) and the desired core matrix test conditions to be simulated. Monte Carlo simulations are used to generate a large, userspecified number of independent trials, each comprising a complete life experiment with multiple cells tested over multiple conditions. The simulated performance of each cell, measured at multiple RPTs, depends on its expected degradation path (given by the degradation model and the specific stress level assigned to the cell) and the random effects due to the error model. For each trial, the model parameters, and therefore cell life, are re-estimated. This set of estimates collected over all trials can be used to understand how the life might vary and help make modifications to the number of cells and test conditions (if necessary) prior to actual cell testing. 
For a full system-level verification (i.e., Stage 3 testing), it is highly recommended that a phenomenological model is developed and supported with a comprehensive suite of electrochemical and diagnostic analyses. Several potentially useful diagnostic techniques have been developed and applied to different lithium-ion chemistries as part of the Department of Energy's Applied Battery Research (ABR) Program. The techniques are documented in a handbook (Reference 10) and the results are detailed in Reference 11. Other factors that can influence life estimation at this stage may include cell balancing and thermal management issues. These effects should also be incorporated into the degradation and error models to provide a complete battery life model.

\subsection{Stress Factor Identification}

The purpose of the core life test matrix is to adequately cover the identified stress factors at various acceleration rates to estimate life with the desired degree of confidence. These stress factors should normally be provided by the manufacturer, or identified with previous Stage 1 test results. Some common battery stressors include temperature, state of charge, energy throughput rate, and pulse power ratings. The number of suggested stress levels per factor is presented in Table 2.1 and the rationale for selecting these stressors is summarized below. Note that this list is not exhaustive, and the number of stress levels is only a recommendation. The actual stress factors and number of levels for the core matrix design will depend on manufacturer recommendations, the number of available cells, test channels, and thermal chambers.

Temperature (T) has been shown to be a major stress factor in most battery chemistries. Assuming that the temperature range does not include off-normal wearout mechanisms, it is expected that the dependence of the rate of performance degradation on temperature will generally be of the Arrhenius type. At least three values of temperature would be needed to assess curvature in the degradation rate with the inverse of absolute temperature. If necessary, a reference temperature should also be added to verify the accuracy of the Arrhenius behavior assumption.

State of charge will also generally affect battery performance and may have a strong effect on life, particularly at higher levels. The required battery energy rating may dictate a high maximum operating SOC. Battery system requirements for cold-cranking power may also dictate that the minimum operating SOC be relatively high to minimize battery size. However, lower SOCs may also be considered for applications such as the charge depleting mode in PHEVs (Reference 3). Therefore, three such levels of operating SOC are suggested to cover the range of possible vehicle application requirements.

The discharge energy throughput rate is expressed in average vehicle speed over the operating life of the battery- 150,000 vehicle miles traveled. Two average speeds of 25 and $20 \mathrm{mph}$ are suggested, which correspond to 6,000 and 7,500 hours of battery cycling, respectively (or, 0.68 and 0.86 years of operating time, respectively). Thus, during the battery's expected life in service of 15 years, over 14 years will be spent in standby (key- 
off) mode at open-circuit conditions. This emphasizes the need for thorough calendar life testing within the core matrix.

Battery cycling normally will be very dynamic, with frequent high-power discharge and regenerative pulses. Having designed the battery system to meet end of life power ratings, the normal usage profiles will only stress the battery to some fraction of these ratings. For example, the HEV Power Assist cycle life goals (Reference 4) allocate percentages of the total cycles to three levels of fractional rated power: $80 \%(240,000)$ of the 300,000 cycles at $60 \%$ of rated power, $15 \%(45,000)$ at $80 \%$ of rated power, and $5 \%$ $(15,000)$ at $95 \%$ of rated power. The effects of pulse power levels on the battery's rate of performance loss may differ between discharge pulses and regenerative pulses. Therefore, independent variation of the power levels for the two types of pulses should be considered.

Table 2.1. Basic stress factors and suggested stress levels for accelerated life testing.

\begin{tabular}{|c|c|c|}
\hline Stress Factor & $\begin{array}{c}\text { Number of } \\
\text { Stress Levels }\end{array}$ & $\begin{array}{c}\text { Suggested } \\
\text { Stress Levels }\end{array}$ \\
\hline Temperature $\left({ }^{\circ} \mathrm{C}\right)$ & 3 to 4 & $\begin{array}{l}\operatorname{Max}\left(e . g ., 55-60^{\circ} \mathrm{C}\right) \\
\operatorname{High}\left(e . g ., 50-55^{\circ} \mathrm{C}\right) \\
\text { Medium }\left(e . g ., 45-50^{\circ} \mathrm{C}\right) \\
\text { Reference }\left(e . g ., 30^{\circ} \mathrm{C}\right) \text { if necessary }\end{array}$ \\
\hline $\begin{array}{l}\text { State of charge }(\%) \\
\text { (maximum operating) }\end{array}$ & 3 & $\begin{array}{l}\text { High }(e . g ., 80 \%) \\
\text { Medium }(e . g ., 60 \%) \\
\text { Low }(e . g ., 40 \%)\end{array}$ \\
\hline $\begin{array}{l}\text { Discharge energy } \\
\text { throughput rate (mph) }\end{array}$ & 3 & $\begin{array}{l}\text { High (e.g., } 25 \mathrm{mph}) \\
\text { Normal (e.g., } 20 \mathrm{mph}) \\
\text { Standby (zero) / Calendar }\end{array}$ \\
\hline \multicolumn{3}{|l|}{$\begin{array}{l}\text { Fraction of pulse } \\
\text { power Rating (\%): }\end{array}$} \\
\hline Discharge pulses & 3 & $\begin{array}{l}\text { High }(e . g ., 100 \%) \\
\text { Medium }(e . g ., 80 \%) \\
\text { Low }(e . g ., 60 \%)\end{array}$ \\
\hline Regenerative pulses & 3 & $\begin{array}{l}\text { High }(e . g ., 100 \%) \\
\text { Medium }(e . g ., 80 \%) \\
\text { Low }(e . g ., 60 \%)\end{array}$ \\
\hline
\end{tabular}




\subsection{Core Life Test Matrix Design}

The core matrix design is usually limited by the supply of cells as well as the number of available test channels and temperature chambers. Given these constraints, a matrix can still be statistically designed to provide informative results based on the number of identified stress factors as well as the interactions between them. Various candidate designs can be considered and each should span the range of experimental conditions of interest. Furthermore, each design should allow for an assessment of interactions between the stress factors. One possible criterion for evaluating the efficacy of a particular design is its ability to successfully estimate the expected life during exposure to one or more stress profiles of interest. The candidate designs may represent variants of a general design in which each variant allocates the available cells differently across the set of experimental conditions. The efficacy of the designs can then be investigated by running the simulation tool (Battery Life Estimator software tool, Reference 2) for each variant and selecting the design that optimizes the criterion of interest.

Use of the BLE software tool requires assumptions about the underlying degradation model as well as the measurement error and the intrinsic variation in performance from cell-to-cell (Reference 12). Depending on the criterion chosen, it may be advantageous to allocate more cells to conditions that exacerbate cell-to-cell variation. Such conditions are likely to be associated with relatively high degradation rates. Another significant criterion for the Stage 2 core matrix design is that it includes at least one previously untested condition from Stage 1 within the expected stress factor range. The simulated response of this condition will be compared with actual test data in Stage 2 to verify the model's accuracy prior to making any life predictions.

In this section, three different example core matrices (minimal, medium, and full factorial) are provided based on some assumed constraints to illustrate the process, as well as the corresponding advantages and disadvantages to each life verification design. For all of these matrix examples, it is assumed that the previous Stage 1 testing consisted of both calendar- and cycle-life testing at three temperatures (e.g., 30,45 , and $60^{\circ} \mathrm{C}$ ) and one SOC (e.g., medium level SOC). It is further assumed that there were three cells assigned to each test condition. This example Stage 1 test matrix is shown in Table 2.2.

Table 2.2. Example USABC test matrix.

\begin{tabular}{ccccc}
\hline $\begin{array}{c}\text { Experiment } \\
\text { Condition }\end{array}$ & $\begin{array}{c}\text { Temperature } \\
\left({ }^{\circ} \mathrm{C}\right)\end{array}$ & $\begin{array}{c}\text { State of } \\
\text { Charge (SOC) }\end{array}$ & Life Test & $\begin{array}{c}\text { Number of } \\
\text { Cells }\end{array}$ \\
\hline 1 & 30 & Medium & Calendar & 3 \\
2 & 45 & Medium & Calendar & 3 \\
3 & 60 & Medium & Calendar & 3 \\
\hline 4 & 30 & Medium & Cycle & 3 \\
5 & 45 & Medium & Cycle & 3 \\
6 & 60 & Medium & Cycle & 3 \\
\hline
\end{tabular}




\subsubsection{Minimal Core Life Test Matrix}

The minimal core life test matrix assumes that only a limited number of cells and/or test channels are available for life verification. Consequently, the Monte Carlo simulations will be based on the original Stage 1 test matrix with one or two additional conditions within the expected stress factor range. These additional conditions should be determined based on manufacturer recommendations and prior knowledge of cell performance. Assuming low manufacturing variability, only the additional conditions need to be verified with actual test data and compared with the simulated results. If the manufacturing variability is not as low as desired, or the cells come from a different lot number, some or all of the previously tested Stage 1 conditions should also be re-verified under Stage 2 testing.

For example, if the Stage 1 test matrix showed an Arrhenius behavior at the higher temperatures, but a different behavior at the reference condition (i.e., 30 or $35^{\circ} \mathrm{C}$ ), then one or two extra temperature conditions could be included in the simulation and verified with test data to more clearly identify the change in electrochemical mechanisms. However, if the behavior for all test temperatures is Arrhenius, then one or two extra SOC conditions could be simulated and verified with test data instead.

The advantage to the minimal core life test matrix is that it requires a small number of cells and testing resources and will be relatively inexpensive. If the model successfully predicts what the test data show for the previously unverified conditions, then the life expectation can be reasonably estimated within the range of assumed stress. The purpose of this minimal matrix design is primarily to determine if the candidate technology is mature enough to consider investing in a more thorough life prediction testing regime (i.e., the medium core life test matrix) for a more reliable estimation of life based on a broader range of stress factor interaction.

The disadvantage to the minimal core life test matrix, however, is that the other stress factors, or the interaction between them, are ignored. This means that the life estimation, although reasonably accurate, is limited to a small set of assumed conditions and is likely not representative of the overall expected use of the battery during its lifetime.

\subsubsection{Medium Core Life Test Matrix}

The medium core life test matrix is designed to further explore the effects of one or two stress factors and their interactions. The core matrix design and optimized allocation of cells can be based on the empirical, semi-empirical, or physics-based model developed from Stage 1 testing or provided by the manufacturer. The matrix design and life estimation process may be iterative based on the completeness of the life model and the anticipated manufacturing variability. Ideally, these iterations will only occur in the simulation, with actual verification testing performed only once. This is possible only if the additional (i.e., previously un-modeled) test conditions included in the Stage 2 core matrix verification testing successfully correspond with the model developed under Stage 1 without any indication of lack-of-fit (Reference 2). However, if verification testing does show evidence of lack-of-fit with the degradation model due to different stress

conditions or stress interactions, the model must be redeveloped using the additional data 
collected from the verification testing and a new estimation of cell life must be made with the simulation tool.

Given a Stage 1 test matrix of three temperatures and one SOC (Table 2.2), a medium core test matrix could be used to investigate the SOC effect more thoroughly. An example test matrix is shown in Table 2.3. Since the Stage 1 test matrix was only at a medium level SOC, the core life test matrix could include the same temperature conditions at a high and low SOC level. This matrix assumes low manufacturing variability such that the Stage 1 tests do not need to be repeated during Stage 2. Test conditions $3,6,11$, and 14 in Table 2.3 are the additional conditions included in the test matrix to verify the accuracy of the model and include previously untested temperatures at different SOC levels. Note also that the number of suggested cells per condition is greater at the low temperature conditions where degradation is expected to occur more slowly. However, these suggested quantities are obviously dependent on the number of available cells, test channels, temperature chambers, and the optimized simulation results. The manufacturing variability should be considered when allocating cells to the test matrix. It is highly recommended that a minimum of three cells per condition is used in any core life test matrix for good statistical results.

Table 2.3. First example of a medium core life test matrix.

\begin{tabular}{ccccc}
\hline $\begin{array}{c}\text { Experiment } \\
\text { Condition }\end{array}$ & $\begin{array}{c}\text { Temperature } \\
\left({ }^{\circ} \mathrm{C}\right)\end{array}$ & $\begin{array}{c}\text { State of } \\
\text { Charge (SOC) }\end{array}$ & Life Test & $\begin{array}{c}\text { Suggested } \\
\text { Number of } \\
\text { Cells }\end{array}$ \\
\hline 1 & 30 & High & Calendar & 6 \\
2 & 30 & Low & Calendar & 6 \\
3 & 37.5 & Low & Calendar & 4 \\
4 & 45 & High & Calendar & 4 \\
5 & 45 & Low & Calendar & 4 \\
6 & 52.5 & High & Calendar & 3 \\
7 & 60 & High & Calendar & 3 \\
8 & 60 & Low & Calendar & 3 \\
\hline 9 & 30 & High & Cycle & 6 \\
10 & 30 & Low & Cycle & 6 \\
11 & 37.5 & Low & Cycle & 4 \\
12 & 45 & High & Cycle & 4 \\
13 & 45 & Low & Cycle & 4 \\
14 & 52.5 & High & Cycle & 3 \\
15 & 60 & High & Cycle & 3 \\
16 & 60 & Low & Cycle & 3 \\
\hline & & & & \\
\hline & 30 & 30 & & 4 \\
\hline
\end{tabular}


Alternatively, if the purpose of the medium core life test matrix is to more thoroughly understand cycle-life effects, then a detailed core matrix with all five stress factors listed in Table 2.1 could be used instead. Typical cycle-life testing requirements (References 3 through 6) include a mixture of power ratings during cycling. For example, the HEV Power Assist requirement (Reference 4) is to complete 240,000 cycles at $60 \%$ of rated power, 45,000 cycles at $80 \%$ of rated power, and 15,000 cycles at $95 \%$ of rated power to successfully meet the 300,000 cycle target. To determine the effect of power rating as an additional stress factor in the core matrix, however, it is important to separate the effects of each power profiles.

The example Stage 1 matrix in Table 2.2 includes three cycle-life test conditions. Table 2.4 shows an example matrix assuming Stage 1 testing was completed with cells that have sufficiently low manufacturing variability such that those test conditions do not have to be repeated. In Table 2.4, the effects of throughput (20 and $25 \mathrm{mph}$ ) and effects of power rating (medium and high level) are considered at three different temperatures and two SOC levels. Cycling at the standard throughput of $20 \mathrm{mph}$ will be based on a single pulse power rating (Section 3.2.1), and results will be compared to the combined cycling that was completed during Stage 1 testing (i.e., the combination of 60, 80, and $95 \%$ power ratings as described above). At the higher throughput, both the single power ratings and combined power ratings must be considered for best comparisons and life estimations. Test conditions 9 and 15 are the additional conditions used to verify the accuracy of the model. Fewer test conditions and stress factor interactions may need to be considered if resources are limited.

Table 2.4. Second example of a medium core life test matrix; cycle-life emphasis.

\begin{tabular}{ccccccc}
\hline $\begin{array}{c}\text { Experiment } \\
\text { Condition }\end{array}$ & $\begin{array}{c}\text { Temperature } \\
\left({ }^{\circ} \mathrm{C}\right)\end{array}$ & $\begin{array}{c}\text { State of } \\
\text { Charge } \\
(\text { SOC) }\end{array}$ & $\begin{array}{c}\text { Throughput } \\
\text { Rate }\end{array}$ & $\begin{array}{c}\text { Discharge } \\
\text { Pulse } \\
\text { (Fraction of } \\
\text { Rating) }\end{array}$ & $\begin{array}{c}\text { Charge } \\
\text { Pulse } \\
\text { (Fraction of } \\
\text { Rating) }\end{array}$ & $\begin{array}{c}\text { Suggested } \\
\text { Number of } \\
\text { Cells }\end{array}$ \\
\hline 1 & 30 & High & 0 & $\mathrm{n} / \mathrm{a}$ & $\mathrm{n} / \mathrm{a}$ & 3 \\
2 & 45 & High & 0 & $\mathrm{n} / \mathrm{a}$ & $\mathrm{n} / \mathrm{a}$ & 3 \\
3 & 60 & High & 0 & $\mathrm{n} / \mathrm{a}$ & $\mathrm{n} / \mathrm{a}$ & 3 \\
\hline 4 & 30 & High & 20 & $95 \%$ & $95 \%$ & 3 \\
5 & 30 & Medium & 20 & $80 \%$ & $80 \%$ & 3 \\
6 & 30 & High & 25 & $95 \%$ & $95 \%$ & 3 \\
7 & 30 & Medium & 25 & $80 \%$ & $80 \%$ & 3 \\
8 & 30 & Medium & 25 & Combined & Combined & 3 \\
9 & 37.5 & Medium & 20 & $95 \%$ & $95 \%$ & 3 \\
10 & 45 & High & 20 & $95 \%$ & $95 \%$ & 3 \\
11 & 45 & Medium & 20 & $80 \%$ & $80 \%$ & 3 \\
12 & 45 & High & 25 & $95 \%$ & $95 \%$ & 3 \\
\hline
\end{tabular}




\begin{tabular}{ccccccc}
\hline $\begin{array}{c}\text { Experiment } \\
\text { Condition }\end{array}$ & $\begin{array}{c}\text { Temperature } \\
\left({ }^{\circ} \mathrm{C}\right)\end{array}$ & $\begin{array}{c}\text { State of } \\
\text { Charge } \\
\text { (SOC) }\end{array}$ & $\begin{array}{c}\text { Throughput } \\
\text { Rate }\end{array}$ & $\begin{array}{c}\text { Discharge } \\
\text { Pulse } \\
\text { (Fraction of } \\
\text { Rating) }\end{array}$ & $\begin{array}{c}\text { Charge } \\
\text { Pulse } \\
\text { (Fraction of } \\
\text { Rating) }\end{array}$ & $\begin{array}{c}\text { Suggested } \\
\text { Number of } \\
\text { Cells }\end{array}$ \\
\hline 13 & 45 & Medium & 25 & $80 \%$ & $80 \%$ & 3 \\
14 & 45 & Medium & 25 & Combined & Combined & 3 \\
15 & 52.5 & High & 25 & $80 \%$ & $80 \%$ & 3 \\
16 & 60 & High & 20 & $95 \%$ & $95 \%$ & 3 \\
17 & 60 & Medium & 20 & $80 \%$ & $80 \%$ & 3 \\
18 & 60 & High & 25 & $95 \%$ & $95 \%$ & 3 \\
19 & 60 & Medium & 25 & $80 \%$ & $80 \%$ & 3 \\
20 & 60 & Medium & 25 & Combined & Combined & 3 \\
\hline
\end{tabular}

The advantage to the medium core life test matrix is that the degradation model can be developed based on two or more stress factors over a reasonably broad range. The additional conditions verify the model's capability to predict behavior at different combinations of these stressors as well. These data provide a much more realistic estimation of the expected life capability of the cells over the anticipated range of use and will help demonstrate the cell technology's readiness for transition to production.

The disadvantage to the medium core life test matrix, however, is that it can require a larger number of cells, test channels, and temperature chambers to fully assess the cell characteristics. However, as discussed above, options are available for more fully assessing the effects of only one or two stressors using relatively smaller matrix sizes. These data can still help further enhance the model development and improve the statistical confidence of the life estimation.

\subsubsection{Full Factorial Core Life Test Matrix}

The full factorial core life test matrix is the most complete approach for successful life estimation, but it can also require access to a very large supply of cells with low manufacturing variability and extensive use of laboratory resources. For Stage 2 level testing and life estimation, it may be useful to use the BLE software tool (Reference 2) to simulate the performance capability of cells under a full-factorial matrix, followed by actual testing for a subset of the conditions. However, this assumes that the degradation model is already well-developed by the end of Stage 1 testing, which is unlikely unless it is supplied by the manufacturer. The full factorial matrix is generally the most useful at the third stage of life verification, where production-ready cells are well characterized and understood. At this stage, the model should be well developed based on previous testing with diagnostic analyses and all significant stress factors should be included in the test matrix. Cell balancing and thermal management issues (where applicable) may also be considered at this stage. 
The five stress factors considered in the matrices shown below are temperature, SOC, throughput rate, discharge pulse rating, and charge pulse rating, as described in Table 2.1, though other relevant stressors may be included as well (e.g., charging rates for PHEVs, pressure, etc.). The BLE software tool is also useful at this point for a preliminary allocation of the number of available batteries per test condition based on the assumed manufacturing variability and measurement error (at this stage of life estimation, both of these error terms should be very small). The core life test matrix consists of two parts: a full-factorial calendar-life matrix and a fractional-factorial cycle life matrix. The recommended calendar-life matrix (see Table 2.5) is a $4 \times 3$ full factorial involving temperature and SOC. Since the throughput rate is zero mph (standby mode), the pulse power rating stressors are not applicable to this matrix.

Table 2.5. Suggested calendar life matrix design.

\begin{tabular}{cccccc}
\hline $\begin{array}{c}\text { Experiment } \\
\text { Condition }\end{array}$ & Temperature & $\begin{array}{c}\text { State of } \\
\text { Charge (SOC) }\end{array}$ & $\begin{array}{c}\text { Throughput } \\
\text { Rate }\end{array}$ & $\begin{array}{c}\text { Discharge } \\
\text { Pulse } \\
\text { (Fraction of } \\
\text { Rating) }\end{array}$ & $\begin{array}{c}\text { Charge } \\
\text { Pulse } \\
\text { (Fraction } \\
\text { of Rating) }\end{array}$ \\
\hline 1 & Reference & Low & Standby & n/a & n/a \\
2 & Reference & Medium & Standby & n/a & n/a \\
3 & Reference & High & Standby & n/a & n/a \\
4 & Medium & Low & Standby & n/a & n/a \\
5 & Medium & Medium & Standby & n/a & n/a \\
6 & Medium & High & Standby & n/a & n/a \\
7 & High & Low & Standby & n/a & n/a \\
8 & High & Medium & Standby & n/a & n/a \\
9 & High & High & Standby & n/a & n/a \\
10 & Max & Low & Standby & n/a & n/a \\
11 & Max & Medium & Standby & n/a & n/a \\
12 & Max & High & Standby & n/a & n/a \\
\hline
\end{tabular}

For cycle-life, two possible matrix designs are given in Tables 2.6 and 2.7. Each is a fractional factorial design given the five stress factors. The first matrix (Table 2.6) is a resolution-III fractional factorial design involving 12 experimental conditions (Reference 13, page 200). If the intent is to assess the main effects and interactions among the stress factors, then the main effects could be separated from one another with this design. However, main effects would be confounded with two-factor interactions. This may not be a serious drawback, considering that the primary objective of the experiment is to verify the projected life-in-service using a variety of experimental conditions, and not necessarily to model life with the cycling stress factors. The relative importance of the calendar life testing should be considered in the overall experiment design. 
Table 2.6. Cycle life matrix design (Design 1).

\begin{tabular}{cccccc}
\hline $\begin{array}{c}\text { Experiment } \\
\text { Condition }\end{array}$ & Temperature & $\begin{array}{c}\text { State of } \\
\text { Charge (SOC) }\end{array}$ & $\begin{array}{c}\text { Throughput } \\
\text { Rate }\end{array}$ & $\begin{array}{c}\text { Discharge } \\
\text { Pulse } \\
\text { (Fraction of } \\
\text { Rating) }\end{array}$ & $\begin{array}{c}\text { Charge } \\
\text { Pulse } \\
\text { (Fraction of } \\
\text { Rating) }\end{array}$ \\
\hline 1 & Medium & Medium & Normal & Medium & Medium \\
2 & Medium & High & Normal & High & Medium \\
3 & Medium & Medium & High & Medium & High \\
4 & Medium & High & High & High & High \\
5 & High & High & High & Medium & Medium \\
6 & High & Medium & High & High & Medium \\
7 & High & Medium & Normal & Medium & High \\
8 & High & High & Normal & High & High \\
9 & Max & High & High & Medium & Medium \\
10 & Max & Medium & Normal & High & Medium \\
11 & Max & High & Normal & Medium & High \\
12 & Max & Medium & High & High & High \\
\hline
\end{tabular}

The second cycle life test matrix (Table 2.7) is a resolution-IV fractional factorial design involving 36 experimental conditions. It is constructed as a $2^{4-1}$ fractional factorial with four stressors (SOC, throughput rate, discharge pulse, charge pulse) crossed with temperature at three levels. Temperature effects are not confounded with any of the other factors. Main effects of the other factors are not confounded with one another or any two-factor interactions. This second cycle life test matrix (Design 2) provides a more comprehensive coverage of the cycling stress factor space than Design 1. In addition, Design 2 would provide information to augment a developer's knowledge base that is deficient in the breadth of stress factors. Although Design 2 has more than twice the number of test conditions, it will not necessarily require as many batteries per test condition. Therefore, the total number of batteries in the core matrix may not be substantially greater for this design.

Table 2.7. Cycle-life matrix design (Design 2).

\begin{tabular}{cccccc}
\hline $\begin{array}{c}\text { Experiment } \\
\text { Condition }\end{array}$ & Temperature & $\begin{array}{c}\text { State of } \\
\text { Charge (SOC) }\end{array}$ & $\begin{array}{c}\text { Throughput } \\
\text { Rate }\end{array}$ & $\begin{array}{c}\text { Discharge } \\
\text { Pulse } \\
\text { (Fraction of } \\
\text { Rating) }\end{array}$ & $\begin{array}{c}\text { Charge } \\
\text { Pulse } \\
\text { (Fraction of } \\
\text { Rating) }\end{array}$ \\
\hline 1 & Medium & Low & Normal & Medium & Medium \\
2 & Medium & Low & Normal & High & High \\
3 & Medium & Low & High & Medium & High \\
\hline
\end{tabular}




\begin{tabular}{|c|c|c|c|c|c|}
\hline $\begin{array}{l}\text { Experiment } \\
\text { Condition }\end{array}$ & Temperature & $\begin{array}{c}\text { State of } \\
\text { Charge (SOC) }\end{array}$ & $\begin{array}{c}\text { Throughput } \\
\text { Rate }\end{array}$ & $\begin{array}{l}\text { Discharge } \\
\text { Pulse } \\
\text { (Fraction of } \\
\text { Rating) }\end{array}$ & $\begin{array}{c}\text { Charge } \\
\text { Pulse } \\
\text { (Fraction of } \\
\text { Rating) }\end{array}$ \\
\hline 4 & Medium & Low & High & High & Medium \\
\hline 5 & Medium & Medium & Normal & Medium & High \\
\hline 6 & Medium & Medium & Normal & High & Medium \\
\hline 7 & Medium & Medium & High & Medium & Medium \\
\hline 8 & Medium & Medium & High & High & High \\
\hline 9 & Medium & High & Normal & Medium & Medium \\
\hline 10 & Medium & High & Normal & High & High \\
\hline 11 & Medium & High & High & Medium & High \\
\hline 12 & Medium & High & High & High & Medium \\
\hline 13 & High & Low & Normal & Medium & Medium \\
\hline 14 & High & Low & Normal & High & High \\
\hline 15 & High & Low & High & Medium & High \\
\hline 16 & High & Low & High & High & Medium \\
\hline 17 & High & Medium & Normal & Medium & High \\
\hline 18 & High & Medium & Normal & High & Medium \\
\hline 19 & High & Medium & High & Medium & Medium \\
\hline 20 & High & Medium & High & High & High \\
\hline 21 & High & High & Normal & Medium & Medium \\
\hline 22 & High & High & Normal & High & High \\
\hline 23 & High & High & High & Medium & High \\
\hline 24 & High & High & High & High & Medium \\
\hline 25 & Max & Low & Normal & Medium & Medium \\
\hline 26 & Max & Low & Normal & High & High \\
\hline 27 & Max & Low & High & Medium & High \\
\hline 28 & Max & Low & High & High & Medium \\
\hline 29 & Max & Medium & Normal & Medium & High \\
\hline 30 & Max & Medium & Normal & High & Medium \\
\hline 31 & Max & Medium & High & Medium & Medium \\
\hline 32 & Max & Medium & High & High & High \\
\hline 33 & Max & High & Normal & Medium & Medium \\
\hline 34 & Max & High & Normal & High & High \\
\hline
\end{tabular}




\begin{tabular}{cccccc}
\hline $\begin{array}{c}\text { Experiment } \\
\text { Condition }\end{array}$ & Temperature & $\begin{array}{c}\text { State of } \\
\text { Charge (SOC) }\end{array}$ & $\begin{array}{c}\text { Throughput } \\
\text { Rate }\end{array}$ & $\begin{array}{c}\text { Discharge } \\
\text { Pulse } \\
\text { (Fraction of } \\
\text { Rating) }\end{array}$ & $\begin{array}{c}\text { Charge } \\
\text { Pulse } \\
\text { (Fraction of } \\
\text { Rating) }\end{array}$ \\
\hline 35 & Max & High & High & Medium & High \\
36 & Max & High & High & High & Medium \\
\hline
\end{tabular}

The advantage to the full factorial core life test matrix is that is provides a life estimate with a high statistical confidence level. All significant stress factors are included in the study, and the interactions between the stressors are considered as well. It should be useful in determining a battery's readiness to transition to full production.

The disadvantage to the full factorial core life test matrix is, however, the very high cost due to the large number of batteries to be tested. Another consideration is the resource limitations with test channels and temperature chambers. At this stage, full size battery packs may be investigated, so test channels with high voltage and current capability may be required.

\subsection{Core Life Test Matrix Verification}

\subsubsection{Preliminary Matrix Design}

Design and verification of the core life test matrix is conducted in three steps. In the first step, a preliminary experiment design is developed by selecting the stress factors, stress levels, and number of test conditions in the matrix. Various matrix designs are described above in Section 2.3 and take into consideration any limitations on the number of available batteries, test channels, and/or temperature chambers. A statistically-designed matrix must be developed with cells allocated as best as reasonably possible within the given constraints.

\subsubsection{Final Matrix Design}

In the second step, Monte Carlo simulation from the BLE software tool (Reference 2) is used to verify and adjust, as necessary, the preliminary matrix design. This is accomplished by generating simulated performance data based on the life model with random variation in cell performance due to the expected levels of the manufacturing variability and measurement error. The simulated results are then analyzed as though they were from an actual test and the cell life is estimated for each trial. The simulation is repeated multiple times (e.g., 1000 trials) for each test condition to assess the uncertainty in the corresponding cell life estimates. This set of cell life estimates collected over all trials can be used as a basis for understanding the likely range for projected life that would be developed from the actual verification experiment assuming that the model assumptions are accurate. If the target life at the desired reference temperature (e.g., 15 years) is met or exceeded by most of the simulation trials, then there 
is sufficient confidence that the actual experiment based on the candidate design will also result in a satisfactory life estimation. The goal is to have at least $90 \%$ of the simulation trials meet or exceed the target life goal. If this is not the case, then an alternative core matrix design needs to be developed or the model will have to be revised. The iterative process of choosing a candidate matrix design and simulating the design must continue until the simulation results indicate that the candidate design will result in a satisfactory life estimate with sufficient confidence.

For a satisfactory estimate with high confidence, the simulated life based on the assumed model must exceed the target life. The margin by which the simulated life exceeds the target will affect the size of the minimal experiment needed for successful life demonstration. If that margin is small, then it is likely that the successful candidate matrix design will require a longer test duration and/or a larger number of cells.

\subsubsection{Verification Testing}

The third and final step is to verify that the model is accurately predicting cell life by comparing the Monte Carlo simulated data with actual test data. Data from the initial characterization testing should be used to verify that the cells and test facilities have achieved the assumed levels of repeatability and accuracy from the simulations. If the noise estimates from these initial test data are significantly different from those assumed in the original experiment design, the design may need to be altered to achieve an acceptable level of confidence in the projection of minimum life in service. The results of this analysis may indicate that corrective actions are required in the matrix design to achieve the goals of the life test experiment. Such actions could include the following:

- Upgrading the test facilities/test procedures to reduce measurement error.

- Adding cells to one or more of the test conditions.

- Extending the test duration, especially for test conditions with the longest expected lives on test.

- Culling of cells from the population to reduce the cell-to-cell variation and, if necessary, manufacturing additional cells to populate the core and supplemental matrices.

\subsection{Supplemental Life Test Matrix Design Requirements}

Various assumptions about cell performance and effects of some stress factors must be made to keep the core matrix at a manageable size. The primary objective of supplemental life testing (where used) is to confirm the validity of those assumptions. Each assumption can be assessed experimentally by comparison with a result from the core life test matrix assuming low manufacturing variability and measurement error. Otherwise, some test conditions from the core matrix may need to be duplicated in the supplemental testing. The following assumptions, posed as null hypotheses, may be the most likely to need such confirmation: 
- The future state of health (SOH) of a cell depends only on the present $\mathrm{SOH}$ and future stresses, independent of the path taken to reach the present $\mathrm{SOH}$.

- Cold-start operation (i.e., cold cranking) does not have an adverse effect on cell life.

- Low-temperature operation, within accepted performance constraints, does not have an adverse effect on cell life.

For each of these assumptions, a corresponding experimental plan is described in the following sections. Other null hypotheses could also be included based on the specific requirements of a given cell chemistry or application. In all cases, the null hypotheses assumptions are to be assessed at an acceptable level of Type I error. The Type I error is the probability that the null hypothesis is rejected when it is in fact true.

Selection of specific test conditions to use in making the comparison with the core matrix test results involves tradeoffs of relative degradation "signal" versus the "noise" (standard deviation) in the estimated degradation. High acceleration rates provide good signal to noise, but the differences between the core matrix and supplemental matrix values of life on test may be easier to detect for lower total performance degradation. Such a tradeoff should be evaluated for any proposed supplemental test condition.

\subsubsection{Experimental Plan to Assess Path Dependence}

Two different null hypotheses can be investigated for this supplemental path dependence test. The first assumption requiring verification is that life estimation can be accurately projected based on only the calendar-life data as long as the cycle-life goals (e.g., 300,000 cycles) are adequately met. This assumption can be verified with a combined calendar- and cycle-life test procedure. The criterion for rejecting the null hypothesis would be based on statistically different life estimations between a pure calendar-life test and a combined calendar/cycle test.

The second assumption is that the rate of change in performance degradation depends only on the present value of degradation and the applied stress factors, not on the history of use that resulted in the present value of degradation (i.e., memory effects). This effect should be studied based on all of the stress factors considered in the core life test matrix. The criterion for rejecting this null hypothesis would be based on statistically significant differences in the degradation rates among the different groups.

Table 2.8 shows a simple path dependence matrix based on three stress factors (life test, temperature, and SOC). Other stress factors, such as pulse power ratings could be considered as well if necessary. Conditions 1 through 5 address the first null hypothesis test concerning combined calendar/cycle life testing. Conditions 6 through 13 address the second assumption about memory effects based on variations to life test (Conditions 6 and 7), temperature (Conditions 8 and 9), and SOC (Conditions 10 and 11). Although not shown in this example matrix, lower temperature conditions could also be included for a more thorough understanding of path dependence. Another component to the memory effect study is to determine the degradation of a set of cells under similar test conditions after different aging histories (Conditions 12 and 13). 
Table 2.8. Example of a path dependence supplemental life test matrix.

\begin{tabular}{cccc}
\hline $\begin{array}{c}\text { Experiment } \\
\text { Condition }\end{array}$ & $\begin{array}{c}\text { Temperature } \\
\left({ }^{\circ} \mathrm{C}\right)\end{array}$ & $\begin{array}{c}\text { State of } \\
\text { Charge (SOC) }\end{array}$ & Life Test \\
\hline 1 & Medium & High & Combined \\
2 & Medium-High & High & Combined \\
3 & High & High & Combined \\
Combined \\
4 & High-Max & High & Combined \\
\hline 5 & Max & High & Cycle/Calendar \\
\hline 6 & High & High & Calendar/Cycle \\
7 & High & High & Calendar \\
\hline 8 & Medium / Max & High & Calendar \\
\hline 9 & Max / Medium & High & Calendar \\
\hline 10 & High & High/Low & Calendar \\
\hline 11 & High & Low/High & Calendar/Cycle \\
\hline 12 & Max / High & High/Medium & Cycle/ Cycle \\
\hline 13 & Medium / High & Low/Medium & Cy \\
\hline
\end{tabular}

\subsubsection{Experimental Plan to Assess Cold-Start Operation}

The null hypothesis for cold-start operation is that periodic cold cranking does not adversely affect battery life. The criterion for rejecting the null hypothesis would be based on statistically significant differences in the performance degradation over the test duration as a result of the periodic cold cranking.

Table 2.9 shows a sample cold-start supplemental matrix for low, medium, and high temperatures, where cell testing is a duplication of the core life matrix conditions with the addition of periodic cold cranking included in the reference performance tests. For example, an additional set of cells could be added to experimental conditions 1 and 9 of Table $2.3\left(30^{\circ} \mathrm{C}\right.$, high SOC, calendar and cycle life, respectively) for the periodic cold crank tests. This will provide the required data at the reference test temperature, but more cells may be needed per condition due to the slow degradation rates. Alternatively, a higher degradation condition could be used (e.g., experimental conditions 7 and 15 of Table 2.3), but the total number of cold crank tests may be fewer than desired based on the more rapid rate of degradation. It could be useful to investigate cold cranking effects at all three temperature ranges, but a subset of conditions could also be considered depending on cell, chamber, and test channel availability. 
Table 2.9. Example of a cold-start supplemental life test matrix.

\begin{tabular}{cccc}
\hline $\begin{array}{c}\text { Experiment } \\
\text { Condition }\end{array}$ & $\begin{array}{c}\text { Temperature } \\
\left({ }^{\circ} \mathrm{C}\right)\end{array}$ & $\begin{array}{c}\text { State of } \\
\text { Charge (SOC) }\end{array}$ & $\begin{array}{c}\text { Life Test (with } \\
\text { periodic cold cranks) }\end{array}$ \\
\hline 1 & Reference & High & Calendar \\
2 & Reference & High & Cycle \\
\hline 3 & Medium & High & Calendar \\
4 & Medium & High & Cycle \\
\hline 5 & High & High & Calendar \\
6 & High & High & Cycle \\
\hline 7 & Max & High & Calendar \\
8 & Max & High & Cycle \\
\hline
\end{tabular}

\subsubsection{Experimental Plan to Assess Low-Temperature Operation}

The null hypothesis for this supplemental test is that battery operation at low temperatures, within accepted performance constraints, does not adversely affect battery life.

This supplemental test is unique in that the test conditions cannot generally be matched to any of the core matrix test conditions. Thus, the selected test temperatures need to be reasonably extreme so as to detect any enhanced degradation. On the other hand, any failure mechanism associated with low-temperature operation should be well understood before life verification testing. If operating limits have been identified to avoid adverse effects on life, the test would be conducted at those limits (e.g., maximum operating SOC, but limited regenerative pulse power). Table 2.10 shows a sample low-temperature test matrix covering two low temperatures and two life tests (calendar and cycle). One group of cells operates well within the specified limits (e.g., "Low" temperature condition), and one operates exactly at the limits (e.g., "Cold" temperature condition). The number of cells in each group would have to be determined on the basis of the acceptable error in rejecting the null hypothesis. As with the other test conditions, the criterion for rejection would be based on a comparison of the degradation rates for the two groups. A further criterion could also be the absence of any physical diagnostic evidence showing that the two groups experienced different low-temperature failure mechanisms. If this is included in the hypothesis test, the number of cells could be minimized for this part of the supplemental matrix. 
Table 2.10. Example of a low-temperature supplemental life test matrix.

\begin{tabular}{cccl}
\hline $\begin{array}{c}\text { Experiment } \\
\text { Condition }\end{array}$ & $\begin{array}{c}\text { Temperature } \\
\left({ }^{\circ} \mathrm{C}\right)\end{array}$ & $\begin{array}{c}\text { State of } \\
\text { Charge }(\mathrm{SOC})\end{array}$ & Life Test \\
\hline 1 & Low & High & Calendar \\
2 & Cold & High & Calendar \\
\hline 3 & Low & High & Cycle \\
4 & Cold & High & Cycle \\
\hline
\end{tabular}




\section{LIFE TEST PROCEDURES}

This section presents various guidelines and some suggested profiles for characterization (Section 3.1), core-life (Section 3.2), and supplemental life (Section 3.3) testing. Successful battery technology life verification will require careful implementation of the procedures specified in one of the standardized testing manuals (References 3 through 6). The procedures described in those manuals generally begin with a set of initial characterization tests prior to life testing. However, if a candidate technology has previously demonstrated successful performance capability relative to the goals for characterization tests such as cold cranking, efficiency, and thermal performance (e.g., during Stage 1 testing), the manufacturer may request that the test articles skip the characterization test. Alternatively, only a subset of the cells may be characterized as a means of verifying the assumed measurement uncertainty and manufacturing variability for the simulation effort. Following initial characterization testing, the core life test matrix that was designed based on the guidelines in Section 2.3 is implemented using standardized calendar and/or cycle life-testing procedures. These data are used to validate the degradation model and provide an overall estimate of life.

The supplemental life test matrix is designed to verify the null hypotheses that certain stressors will not impact cell life. As such, the test matrix design will usually be chemistry-specific and based on manufacturer's recommendations. Three primary types of supplemental life test are envisioned as part of the overall technology life verification program. They include (a) the effects of path dependence, (b) periodic verification of cold-cranking power, and (c) verification of low-temperature operation. Other relevant supplemental tests could be included as well if needed. Results from these tests will be compared with the core matrix test results to assess the effects, if any, of the supplemental test conditions on the projected life in service for the candidate technology.

\subsection{Initial Characterization Tests}

\subsubsection{General Test Conditions and Scaling}

Certain standard checks should be made of all cells in their as-received condition to ensure that the cells have not been damaged in shipment to the test facility. These checks will minimally include (a) visual inspection for damage, (b) measurement of open-circuit voltage, and (c) a reference measurement of AC impedance at $1 \mathrm{kHz}$ if possible. All cells should also be weighed on receipt.

A life test regime must establish and maintain a consistent set of conditions under which tests are conducted. These include device environment (primarily temperature), test limitations imposed by either the application or the device under test, and the appropriate scaling of test loading for the target application. These limitations will typically be provided in a cell-specific test plan.

Accurate temperature control and measurement is especially important during characterization and the reference performance tests because they are used to track 
performance changes over time, which are the basis for verification of life. All testing should be conducted using environmental chambers.

Operating limits for the test articles may vary between target applications and may include technology-specific constraints. In this manual, such limits are assumed to be controlled as required to meet the objectives of the life verification testing and implemented in modified test procedures as appropriate.

The allowable operating voltage range and corresponding state of charge range for a device is established by the manufacturer. For purposes of this manual, an applicationspecific operating range (that may be a subset of this allowable range) is specified, typically in a test plan for the life test program.

Scaling of test loads is necessarily done using the methods defined for the specified application (e.g., EV, HEV, or PHEV) so that cell performance can be fairly compared to the application targets. Test power levels for devices are scaled using a "battery size factor" (BSF) which is the minimum number of cells or modules expected to be required to meet all the performance and life goals. The determination and use of the BSF based on specific goals and requirements is described in detail in References 3 through 6.

\subsubsection{AC Impedance Measurements}

A full spectrum sweep of AC complex impedance (with a frequency range typically defined in a cell-specific test plan) can be conducted on all cells at beginning of life to help identify any anomalous characteristics within the cells. The results can be useful when allocating cells to the core and supplemental life matrices. Standard, commercially available frequency response analyzers can be useful for these measurements, but the measurement time can be lengthy depending on system settings and it may be useful to perform the measurements on only a subset of the cells if time and resources are limited for Stage 2 testing. At a minimum, AC impedance should be measured on the same subset of cells at the end of testing as well. Alternatively, rapid impedance spectrum measurements (References 7-8), if available, can be used to measure the impedance on all (or some) of the cells at beginning of life and at each reference performance test to gauge degradation as a function of aging for the core and/or supplemental matrices.

\subsubsection{Minimum Characterization Testing}

Stage 1 testing may show that the candidate technology can successfully meet the required performance goals (e.g., cold cranking, thermal performance, efficiency, etc.) at characterization. If so, the manufacturer could request that characterization be skipped for Stage 2 testing. However, the test articles should still be subjected to the minimum characterization testing specified in References 3 through 6 to ensure that the measurement uncertainty and cell-to-cell variation is consistent with the assumed values during simulation. This would generally include (1) verification of rated capacity at the $\mathrm{C}_{1} / 1$ rate and capacity stability (e.g., to within $\pm 2 \%$ for last three successive discharges), and (2) verification of pulse power capabilities and usable energy. It is also recommended that a small subset of test articles be subjected to the full cadre of 
characterization tests to determine the impact (if any) they have on life estimation as part of the supplemental matrix.

\subsection{Core Life Tests}

Specific test profiles and procedures are detailed in the standardized test manuals (References 3 through 6) and should be implemented for core matrix testing. The test matrices in these manuals typically include changes in temperature and/or state-ofcharge. Therefore, this section describes some suggested changes to example profiles for the purpose of determining the effects of the pulse power and throughput stress factors. Similar methodologies and can be used for other identified stress factors as well if necessary.

\subsubsection{Pulse Power Studies}

Cycle-life aging usually requires a combination of test profiles with different pulse power levels. The hybrid electric power-assist charge-sustaining cycle-life test profile (Reference 4), for instance, requires 240,000 cycles of a Baseline profile with $60 \%$ pulse power rating, 45,000 cycles of a $95^{\text {th }}$ Percentile profile with $80 \%$ of the power rating, and the remaining 15,000 cycles from a $99^{\text {th }}$ Percentile profile with nearly $100 \%$ of the power rating. Successful Stage 1 testing would have demonstrated the test article's capability to meet at least 300,000 cycles with a combination of these three profiles. Therefore, Stage 2 testing should isolate one profile from another to determine the individual effects of the various pulse power stress levels.

Separating the effects between discharge and regen power levels require modifications to the predefined profiles. The Baseline $25 \mathrm{Wh}$ minimum power-assist HEV cycle-life test profile is shown in Table 3.1 (Reference 4) and includes a "Launch" discharge and "Regen" power pulse at $60 \%$ of the target (i.e., $15 \mathrm{~kW}$ "Launch" and $12 \mathrm{~kW}$ "Regen" for given target levels of 25 and $20 \mathrm{~kW}$, respectively). This profile has a $90 \%$ round-trip efficiency since $25 \mathrm{Wh}$ are removed and $27.8 \mathrm{Wh}$ are returned within the 90 -s profile. If the "Launch" pulse is increased to $20 \mathrm{~kW}$ (i.e., $80 \%$ of the power rating), then the "Engine-Off" pulse power level must be decreased to $2.5 \mathrm{~kW}$ for 20 seconds to maintain a $25 \mathrm{Wh}$ discharge energy throughput. Using the Power-based Cycle Life Efficiency Model (P-CLEM) from the HEV Manual (Reference 4), the resulting modified Baseline profile is shown in Table 3.2. The "Cruise" power level was increased from $-1.15 \mathrm{~kW}$ to $-1.24 \mathrm{~kW}$ and the profile round-trip efficiency was reduced to approximately $85 \%$.

Similarly, if the "Launch" Pulse is increased to $24 \mathrm{~kW}$ (i.e., 96\% of the power rating), then the "Engine-Off" pulse power level must be decreased to $2.1 \mathrm{~kW}$ for 20 seconds to ensure a $25 \mathrm{Wh}$ discharge energy throughput. From P-CLEM, the modified Baseline profile is shown in Table 3.3. The "Cruise" power level was increased to $-1.36 \mathrm{~kW}$ and the profile round-trip efficiency was reduced to $79 \%$. Figure 1 shows a graphical representation of cycle-life profiles based on the modified discharge pulse power levels from Tables 3.1 through 3.3. 
Table 3.1. Baseline 25-Wh cycle life test profile (Reference 4).

\begin{tabular}{ccccccc}
\hline Pulse & $\begin{array}{c}\text { Time } \\
\text { Increment } \\
(\mathrm{s})\end{array}$ & $\begin{array}{c}\text { Cumulative } \\
\text { Time } \\
(\mathrm{s})\end{array}$ & $\begin{array}{c}\text { System } \\
\text { Power } \\
(\mathrm{kW})\end{array}$ & $\begin{array}{c}\text { Energy } \\
\text { Increment } \\
(\mathrm{Wh})\end{array}$ & $\begin{array}{c}\text { Cumulative } \\
\text { Increment } \\
(\mathrm{Wh})\end{array}$ & $\begin{array}{c}\text { Power } \\
\text { Rating } \\
(\%)\end{array}$ \\
\hline Engine-Off & 20 & 20 & 3.00 & 16.67 & 16.67 & 100 \\
Launch & 2 & 22 & 15.00 & 8.33 & 25.00 & 60 \\
Cruise & 66 & 88 & -1.15 & -21.11 & 3.89 & \\
Regen & 2 & 90 & -12.00 & -6.67 & -2.78 & 60 \\
\hline
\end{tabular}

Table 3.2. Adjusted Baseline 25 -Wh cycle life test profile ( $80 \%$ discharge power).

\begin{tabular}{ccccccc}
\hline Pulse & $\begin{array}{c}\text { Time } \\
\text { Increment } \\
(\mathrm{s})\end{array}$ & $\begin{array}{c}\text { Cumulative } \\
\text { Time } \\
(\mathrm{s})\end{array}$ & $\begin{array}{c}\text { System } \\
\text { Power } \\
(\mathrm{kW})\end{array}$ & $\begin{array}{c}\text { Energy } \\
\text { Increment } \\
(\mathrm{Wh})\end{array}$ & $\begin{array}{c}\text { Cumulative } \\
\text { Increment } \\
(\mathrm{Wh})\end{array}$ & $\begin{array}{c}\text { Power } \\
\text { Rating } \\
(\%)\end{array}$ \\
\hline Engine-Off & 20 & 20 & $\mathbf{2 . 5 0}$ & 13.89 & 13.89 & 100 \\
Launch & 2 & 22 & $\mathbf{2 0 . 0 0}$ & 11.11 & 25.00 & $\mathbf{8 0}$ \\
Cruise & 66 & 88 & $\mathbf{- 1 . 2 4}$ & -22.66 & 2.34 & \\
Regen & 2 & 90 & -12.00 & -6.67 & -4.33 & 60 \\
\hline
\end{tabular}

Table 3.3. Adjusted Baseline 25 -Wh cycle life test profile ( $96 \%$ discharge power).

\begin{tabular}{ccccccc}
\hline Pulse & $\begin{array}{c}\text { Time } \\
\text { Increment } \\
(\mathrm{s})\end{array}$ & $\begin{array}{c}\text { Cumulative } \\
\text { Time } \\
(\mathrm{s})\end{array}$ & $\begin{array}{c}\text { System } \\
\text { Power } \\
(\mathrm{kW})\end{array}$ & $\begin{array}{c}\text { Energy } \\
\text { Increment } \\
(\mathrm{Wh})\end{array}$ & $\begin{array}{c}\text { Cumulative } \\
\text { Increment } \\
(\mathrm{Wh})\end{array}$ & $\begin{array}{c}\text { Power } \\
\text { Rating } \\
(\%)\end{array}$ \\
\hline Engine-Off & 20 & 20 & $\mathbf{2 . 1 0}$ & 11.67 & 11.67 & 100 \\
Launch & 2 & 22 & $\mathbf{2 4 . 0 0}$ & 13.33 & 25.00 & $\mathbf{9 6}$ \\
Cruise & 66 & 88 & $\mathbf{- 1 . 3 6}$ & -24.96 & 0.04 & \\
Regen & 2 & 90 & -12.00 & -6.67 & -6.63 & 60 \\
\hline
\end{tabular}




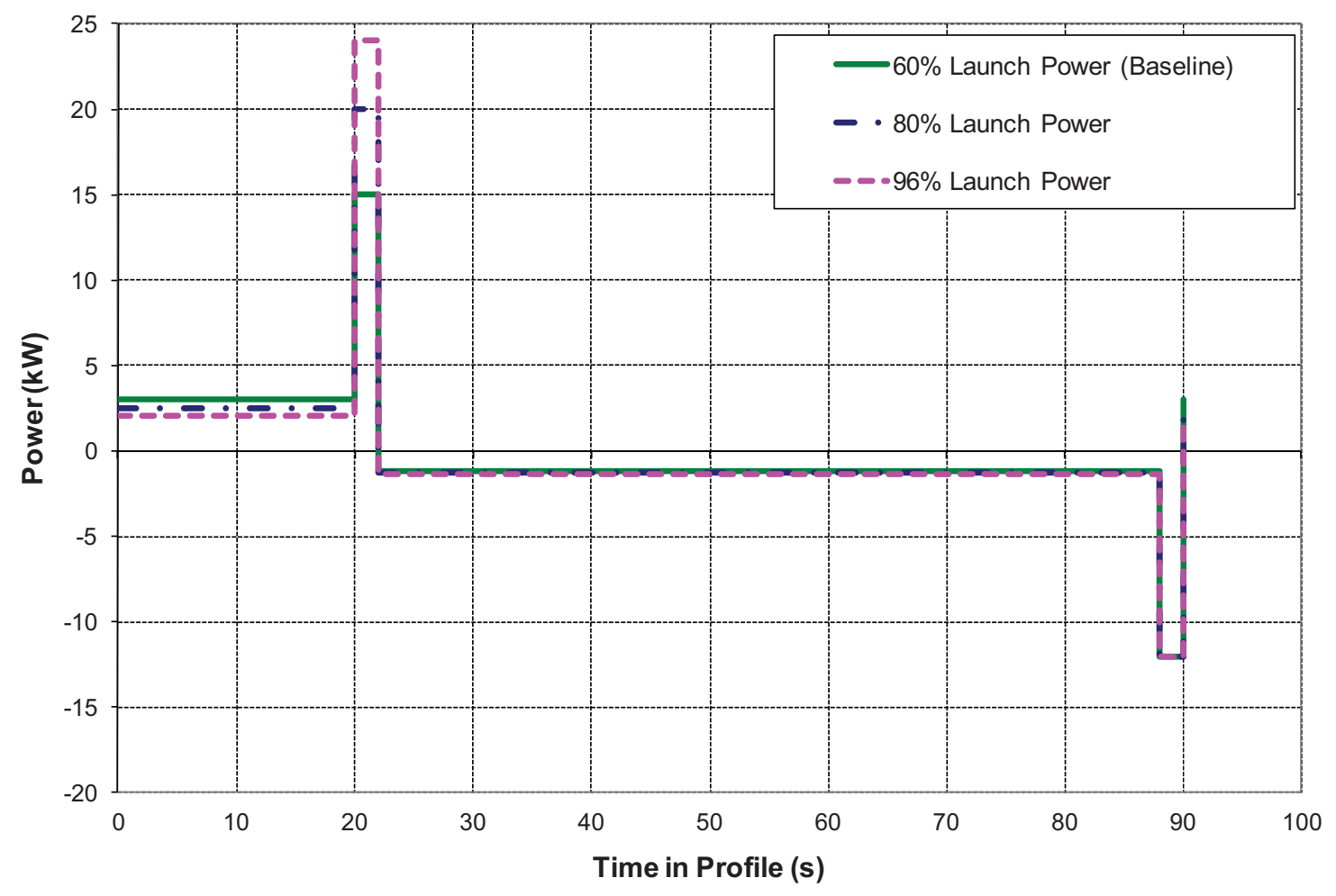

Figure 1. Adjusted $25 \mathrm{Wh}$ power-assist Baseline cycle life test profiles (discharge)

Tables 3.4 and 3.5 show the profile modifications based on adjusting the "Regen" pulse instead of the "Launch" pulse from $60 \%$ to $80 \%$ and $95 \%$ of the target, respectively, using the P-CLEM tool. When increasing the "Regen" pulse to $-16 \mathrm{~kW}(80 \%$ of the power target, Table 3.4), the "Cruise" step power is reduced to $-1.05 \mathrm{~kW}$ and the profile efficiency drops to approximately $89 \%$. If the "Regen" power is increased to $-19 \mathrm{~kW}$ ( $95 \%$ of the power target, Table 3.5), the "Cruise" step power is reduced to $-0.98 \mathrm{~kW}$ and the profile efficiency drops to about $88 \%$. Figure 2 shows the resulting $25 \mathrm{Wh}$ cycle-life profiles based on the modified charge pulse power levels.

Other combinations of power level adjustments can be made to this cycle-life profile as needed. For example, Table 2.7 requires a mixture of "medium" discharge pulse power levels and "high" regen power levels (e.g., Condition 3). This corresponds to an $80 \%$ "Launch" power level $(20 \mathrm{~kW})$ and a 95\% "Regen" pulse level $(-19 \mathrm{~kW})$. The P-CLEM tool can be used to adjust the power levels as required while retaining the appropriate energy throughput. Similar pulse power modifications can be implemented for the 50 Wh maximum power-assist cycle-life profile as well (Reference 4). 
Table 3.4. Adjusted Baseline 25-Wh cycle life test profile ( $80 \%$ regen power).

\begin{tabular}{ccccccc}
\hline Pulse & $\begin{array}{c}\text { Time } \\
\text { Increment } \\
(\mathrm{s})\end{array}$ & $\begin{array}{c}\text { Cumulative } \\
\text { Time } \\
(\mathrm{s})\end{array}$ & $\begin{array}{c}\text { System } \\
\text { Power } \\
(\mathrm{kW})\end{array}$ & $\begin{array}{c}\text { Energy } \\
\text { Increment } \\
(\mathrm{Wh})\end{array}$ & $\begin{array}{c}\text { Cumulative } \\
\text { Increment } \\
(\mathrm{Wh})\end{array}$ & $\begin{array}{c}\text { Power } \\
\text { Rating } \\
(\%)\end{array}$ \\
\hline Engine-Off & 20 & 20 & 3.00 & 16.67 & 16.67 & 100 \\
Launch & 2 & 22 & 15.00 & 8.33 & 25.00 & 60 \\
Cruise & 66 & 88 & $\mathbf{- 1 . 0 5}$ & -19.24 & 5.76 & \\
Regen & 2 & 90 & $\mathbf{- 1 6 . 0 0}$ & -8.89 & -3.13 & $\mathbf{8 0}$ \\
\hline
\end{tabular}

Table 3.5. Adjusted Baseline 25-Wh cycle life test profile (95\% regen power).

\begin{tabular}{ccccccc}
\hline Pulse & $\begin{array}{c}\text { Time } \\
\text { Increment } \\
(\mathrm{s})\end{array}$ & $\begin{array}{c}\text { Cumulative } \\
\text { Time } \\
(\mathrm{s})\end{array}$ & $\begin{array}{c}\text { System } \\
\text { Power } \\
(\mathrm{kW})\end{array}$ & $\begin{array}{c}\text { Energy } \\
\text { Increment } \\
(\mathrm{Wh})\end{array}$ & $\begin{array}{c}\text { Cumulative } \\
\text { Increment } \\
(\mathrm{Wh})\end{array}$ & $\begin{array}{c}\text { Power } \\
\text { Rating } \\
(\%)\end{array}$ \\
\hline Engine-Off & 20 & 20 & 3.00 & 16.67 & 16.67 & 100 \\
Launch & 2 & 22 & 15.00 & 8.33 & 25.00 & 60 \\
Cruise & 66 & 88 & $\mathbf{- 0 . 9 8}$ & -17.89 & 7.11 & \\
Regen & 2 & 90 & $\mathbf{- 1 9 . 0 0}$ & -10.56 & -3.45 & $\mathbf{9 6}$ \\
\hline
\end{tabular}

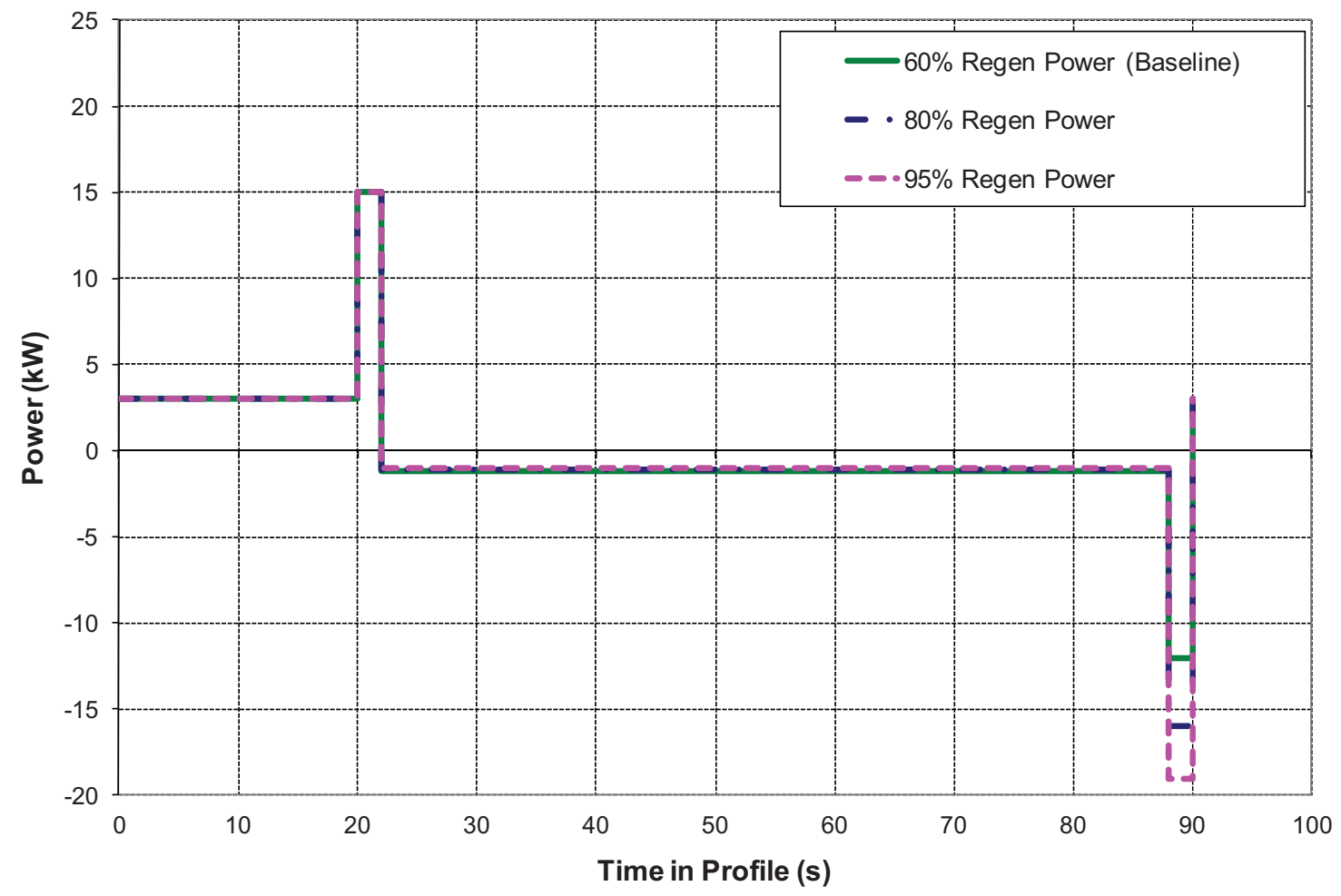

Figure 2. Adjusted 25 Wh power-assist Baseline cycle life test profiles (charge) 


\subsubsection{Throughput Studies}

The HEV cycle-life profile (Reference 4) has a duration of 90-s and requires 300,000 cycles to adequately meet the targets of 150,000 miles. This corresponds to 7500 hours of continuous cycling at an assumed average speed of $20 \mathrm{mph}$. For throughput studies, the average speed can be increased, thus reducing the duration of the cycle-life profile. For example, if the average speed were increased to $25 \mathrm{mph}$, then the cycle time must be reduced to 6000 hours which results in a profile duration of only 72 -s. Table 3.6 shows the adjusted pulse times for the increased throughput and Figure 3 shows the resulting profile based on the P-CLEM tool. The "Engine-Off" profile duration was reduced from 20-s to 15-s and the "Launch" pulse was increased from 2-s to 3-s to ensure that $25 \mathrm{Wh}$ are removed during the discharge. The "Cruise" pulse duration was reduced from 66-s to $52-\mathrm{s}$ and the power level was increased from $-1.15 \mathrm{~kW}$ to $-1.51 \mathrm{~kW}$ to yield an overall profile efficiency of approximately $88 \%$. Similar modifications can be made to the 50 Wh HEV cycle-life profile as well.

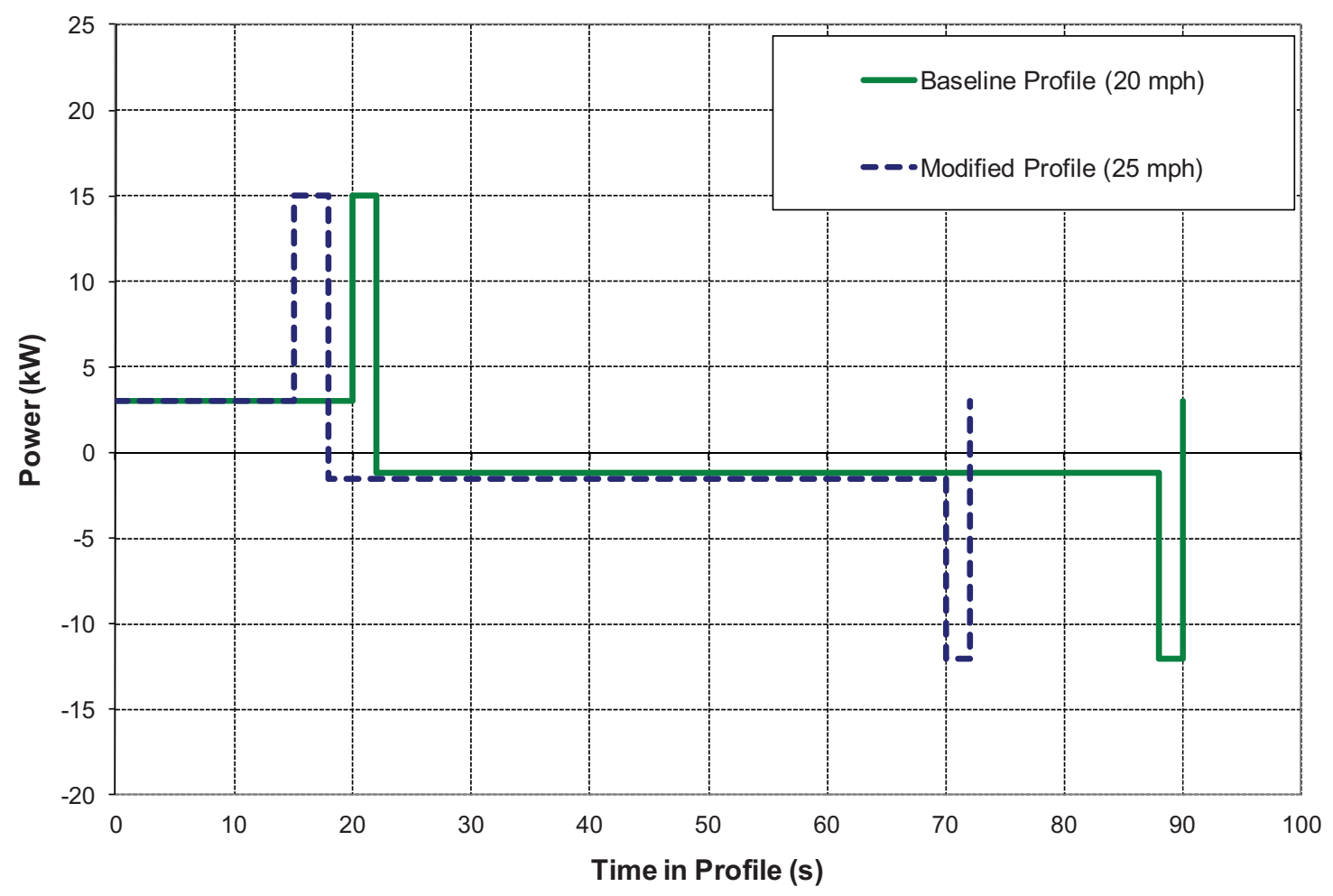

Figure 3. Adjusted $25 \mathrm{Wh}$ power-assist Baseline cycle life test profiles ( $25 \mathrm{mph})$ 
Table 3.6. Adjusted Baseline 25-Wh cycle life test profile ( $25 \mathrm{mph})$.

\begin{tabular}{ccccccc}
\hline Pulse & $\begin{array}{c}\text { Time } \\
\text { Increment } \\
(\mathrm{s})\end{array}$ & $\begin{array}{c}\text { Cumulative } \\
\text { Time } \\
(\mathrm{s})\end{array}$ & $\begin{array}{c}\text { System } \\
\text { Power } \\
(\mathrm{kW})\end{array}$ & $\begin{array}{c}\text { Energy } \\
\text { Increment } \\
(\mathrm{Wh})\end{array}$ & $\begin{array}{c}\text { Cumulative } \\
\text { Increment } \\
(\mathrm{Wh})\end{array}$ & $\begin{array}{c}\text { Power } \\
\text { Rating } \\
(\%)\end{array}$ \\
\hline Engine-Off & $\mathbf{1 5}$ & 15 & 3.00 & 12.5 & 12.50 & 100 \\
Launch & $\mathbf{3}$ & 18 & 15.00 & 12.5 & 25.00 & 60 \\
Cruise & $\mathbf{5 2}$ & 70 & $\mathbf{- 1 . 5 1}$ & -21.82 & 3.18 & \\
Regen & 2 & 72 & -12.00 & -6.67 & -3.49 & 60 \\
\hline
\end{tabular}

\subsection{Supplemental Life Tests}

The objective of the supplemental life tests is to assess the effects of potentially significant variations in operating and reference test conditions on battery life. Three such variations have been identified as candidates for inclusion in a technology life verification program. Other variations may be appropriate for some technologies. Because candidate technologies are expected to be insensitive to these variations, the supplemental life tests are designed to verify null hypotheses by comparison with similar tests from the core matrix. This reduces the number of test conditions required in the core matrix to just the essential calendar and cycling variations.

The three identified supplemental test variations are (1) alternate sequences of combined calendar and cycle life conditions to verify the path-independence (i.e., memoryless effects) of the cell performance degradation, (2) application of cold-cranking tests as part of the periodic RPT regime, and (3) cycling at low temperature. Testing requirements for the supplemental test matrix are identical to those for the corresponding groups in the core life test matrix. Setup requirements and suggested procedures for these supplemental life tests are provided in the following sections, though manufacturers may also recommend their own test sequence based on chemistry.

\subsubsection{Path Dependence Studies}

Path dependence studies are designed to determine the effects of combined stress factors during life testing. A key component to path dependence is the effect of past history on future performance degradation. A "memoryless" process is one in which the future degradation is solely dependent on the current state-of-health and the future environment, as illustrated in Figure 4. This section describes procedures for path dependence studies on life profiles (calendar and cycle life), temperature, and SOC swings. Other combinations such as both temperature and SOC swings could also be considered in the supplemental matrix design as well. 


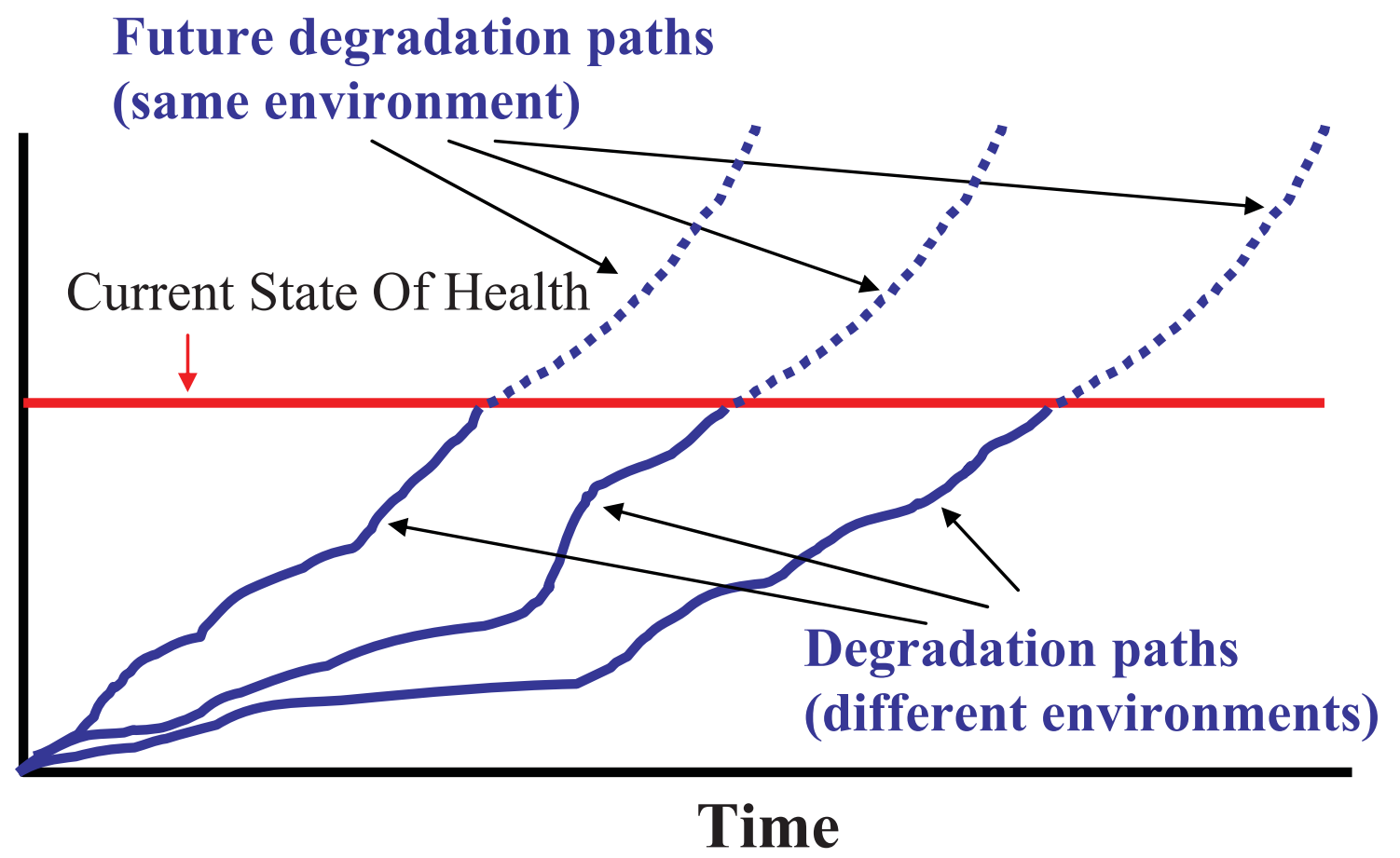

Figure 4. Illustration of a memoryless process

\subsubsection{Life Testing Profile Path Dependence}

Two different approaches are suggested for the life testing profile path dependence study. For the first approach, one group will be tested under the specified cycle life test conditions at a designated temperature and SOC until the cells, on average, reach onehalf of the expected power fade for the given test condition. The cells will then continue testing under the specified calendar life test conditions for the remainder of the overall test program. The second group will be tested under the specified calendar life test conditions until the cells, on average, reach the same value of power fade as the first group reached when they were switched from the cycle life to calendar life regime. Each group of cells should then be subjected to the same environmental conditions for a period life aging, calendar or cycle, to determine the effect (if any) of the previous history.

An alternative approach is to determine the calendar-life at each test temperature during standardized USABC testing (i.e., Stage 1), and intermix the total number of required cycle-life profiles (e.g., 300,000 cycles) within the expected calendar-life at each test temperature. For example, if previous testing revealed a two year calendar life for a set of cells at $60^{\circ} \mathrm{C}$ with reference performance tests every month, then each calendar-life period for a combined calendar/cycle profile would include $12.5 \mathrm{k}$ cycles $(300,000$ cycles divide by 24 months) with standard calendar-life testing for the remainder of the period before an RPT.

\subsubsection{Temperature Path Dependence}

A direct way to assess whether or not the degradation process associated with a variable temperature stress is "memoryless" is to perform non-isothermal tests. Subject one group 
to the high temperature condition at a designated SOC until the cells, on average, reach one-half of the expected power fade for the given test condition. Then subject these cells to the specified lower temperature condition for the remainder of the overall test program. A second group will undergo the reverse process where it starts at the low temperature test conditions until the cells, on average, reach the same value of power fade as the first group reached when they were switched from the high temperature to low temperature regime. Each group of cells should then be subjected to the same temperature conditions for a period of time to determine the effect (if any) of the previous history.

Alternatively, some cells could be exposed to isothermal stress while other cells are targeted to experience non-isothermal exposure. Some of the cells could be exposed to increasing stress levels while others to decreasing stress levels. The temperature profiles could be discrete (e.g., step changes) or continuous (e.g., sinusoidal). The frequency and amplitude of the temperature variations could also be verified in this type of study depending on available cells, temperature chambers, and test channels. Model development and parameter estimation for this type of test matrix are discussed in Reference 2.

\subsubsection{State-of-Charge Path Dependence}

Similar to the approach used for temperature path dependence, a direct way to assess whether or not the degradation process associated with a variable SOC stress is "memoryless" is to perform tests with variations in SOC swings. One group would be life tested at a high SOC condition at a designated temperature until the cells, on average, reach one-half of the expected power fade for the given test condition. The cells would then continue testing at a specified lower SOC condition for the remainder of the overall test program. The second group would be tested under the specified low SOC test conditions until the cells, on average, reach the same value of power fade as the first group reached when they were switched from the high SOC to low SOC regime. Each group of cells should then be subjected to the same SOC condition for a period of time to determine the effect (if any) of the previous history.

Alternatively, some cells could be exposed to constant SOC conditions while other cells are targeted to experience variations in SOC. Some of the cells could be exposed to increasing stress levels while others to decreasing stress levels. The SOC swings could be modified based on profile amplitude and duration depending on available cells, temperature chambers, and test channels. For example, various combinations of PHEV charge-sustaining and charge depleting profiles could be implemented using variations in SOC swings based on the profiles defined in Reference 3.

\subsubsection{Cold-cranking Power Verification Tests}

Two groups of cells will be used in this supplemental life test. One group will be calendar life tested at the same (elevated) test temperature as one of the core life test matrix conditions. Assuming low manufacturing variability, the cells tested under the core matrix could be used for comparison instead of re-testing the same condition. The second group will be cycle life tested at the same (elevated) test temperature and pulse power profile as one of the core life test matrix conditions. Both supplemental groups 
will be subjected to a cold-cranking test at each specified RPT interval throughout the duration of the overall test program. The requirements and procedures for the calendar life, cycle life, and cold-cranking tests are as previously specified above and/or in the appropriate testing manual (Reference 3 through 6).

\subsubsection{Low-temperature Operation Tests}

Two groups of cells will be used in this supplemental life test. Both groups will be cycle life tested at a different specified test temperature below the reference temperature. The power profile will be the same for both groups, with a limited regenerative pulse power to be specified by the cell manufacturer if needed. This special power profile will be developed and agreed upon jointly by USABC and the manufacturer. It will be applied at both test temperatures, with the expectation that there will be no difference in the life-ontest between the two groups compared to standardized testing from the core matrix. 


\section{DATA ANALYSIS AND REPORTING}

The standardized methods for analysis and reporting of the performance test data are provided in the appropriate USABC Manuals (References 3 through 6). The purpose of this section is to provide some additional analysis tools that are useful for successful life prediction at a Stage 2 level of testing, especially for the supplemental life test results. Since cell testing at Stage 2 may have a higher variability than desired, Section 4.1 primarily addresses how a consistent subset of cells might be selected for testing based on characterization data. The principal objectives of characterization testing are to establish the baseline performance of the test cell population, assess the variability of the population, and assign cells from the population to the core and supplemental life test matrices. The consistency of cells selected will help to ensure that conclusions drawn from the testing are not spurious. Section 4.2 is a brief discussion on assessing the core life test results based on the procedures defined by the USABC Manuals. Section 4.3 addresses the data analyses required to support the null hypothesis tests for the lives on test at the supplemental test conditions. All analyses are directed at reaching a valid conclusion regarding the life capabilities of the candidate technology.

\subsection{Initial Performance Characterization Test Results}

\subsubsection{Rank Ordering of Cells}

Under ideal conditions, the cell manufacturing variability will be sufficiently low such that test articles can be distributed into the core and supplemental matrices at random. In the absence of low cell-to-cell differences, however, a methodology has been developed to "randomly" assign the cells to the test matrices such that the average of each test group is representative of the overall population. As an example, two of the more typical degradation parameters measured from characterization testing and the RPTs will be resistance $(R)$ and capacity $(Q)$. Equations (4) and (5) show the cell-specific deviation in resistance and capacity, respectively, from the overall cell average. To decrease the effects of manufacturing deviation, the cells can then be randomly assigned to each matrix condition such that the overall group average deviation within a test condition is less than or equal to some predetermined limit (e.g., a deviation limit of 0.5). The process flow diagram for this approach is shown in Figure 5. A random sample of cells is chosen to fill a matrix condition such that there are no duplicates (i.e., no cells are randomly assigned more than once) or repeats (i.e., a cell is not selected if it has already been assigned to another test condition). If the group average deviation is below the predetermined limit, then the cells are kept in the matrix condition. Otherwise, they are placed back in the pool of cells again, and the process repeats. Figure 6 shows the difference between the rank ordering of cells (shown with the blue diamond symbol) and a completely random cell assignment (shown with the pink squares) to a given test matrix. As shown, the group averages for the rank ordering of cells are much tighter compared to a purely random assignment of cells. 


$$
\begin{aligned}
& R_{d e v}=\frac{R_{c e l l}-R_{a v g}}{R_{s t d}} \\
& Q_{d e v}=\frac{Q_{c e l l}-Q_{a v g}}{Q_{s t d}}
\end{aligned}
$$

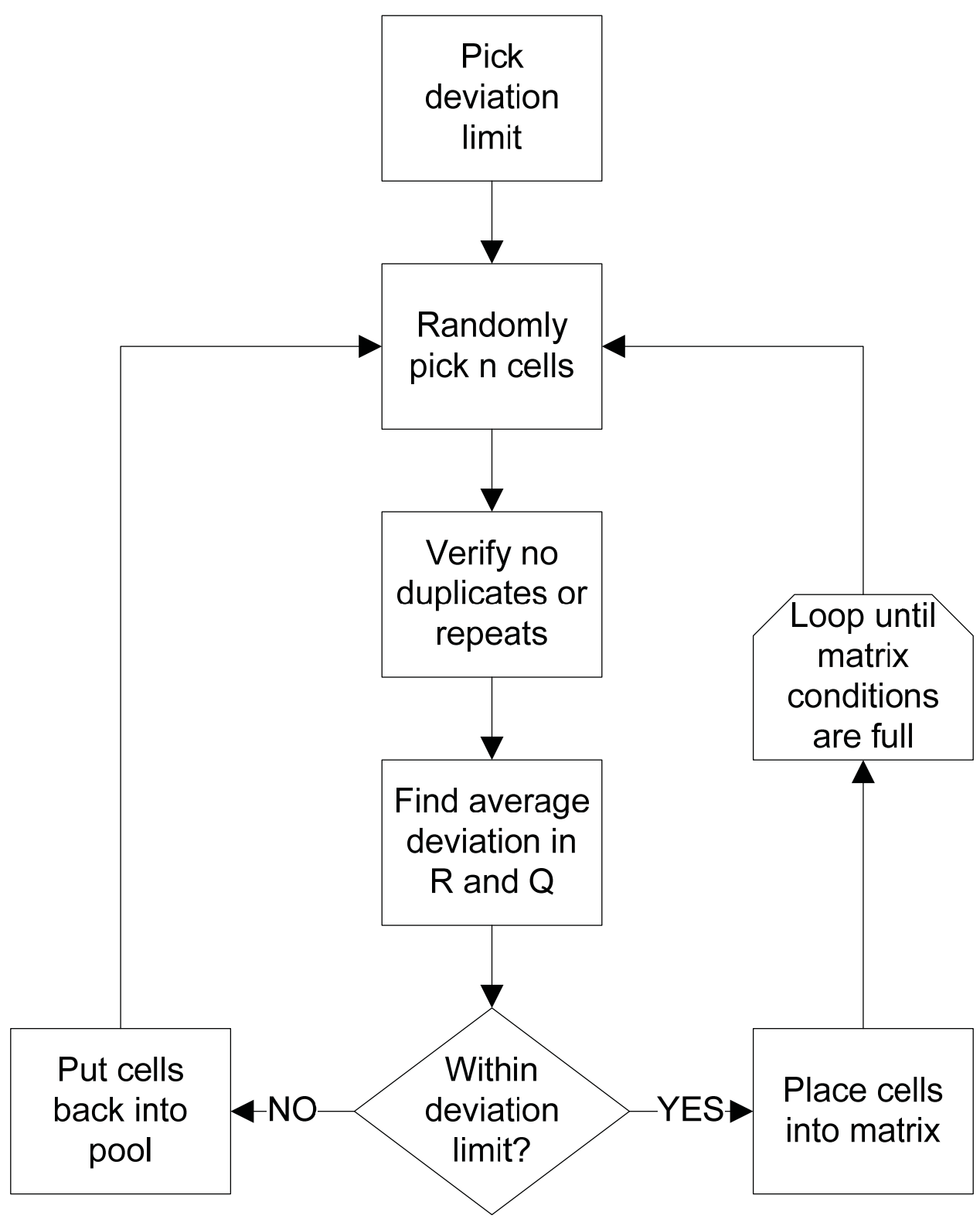

Figure 5. Rank ordering of cells flow diagram 


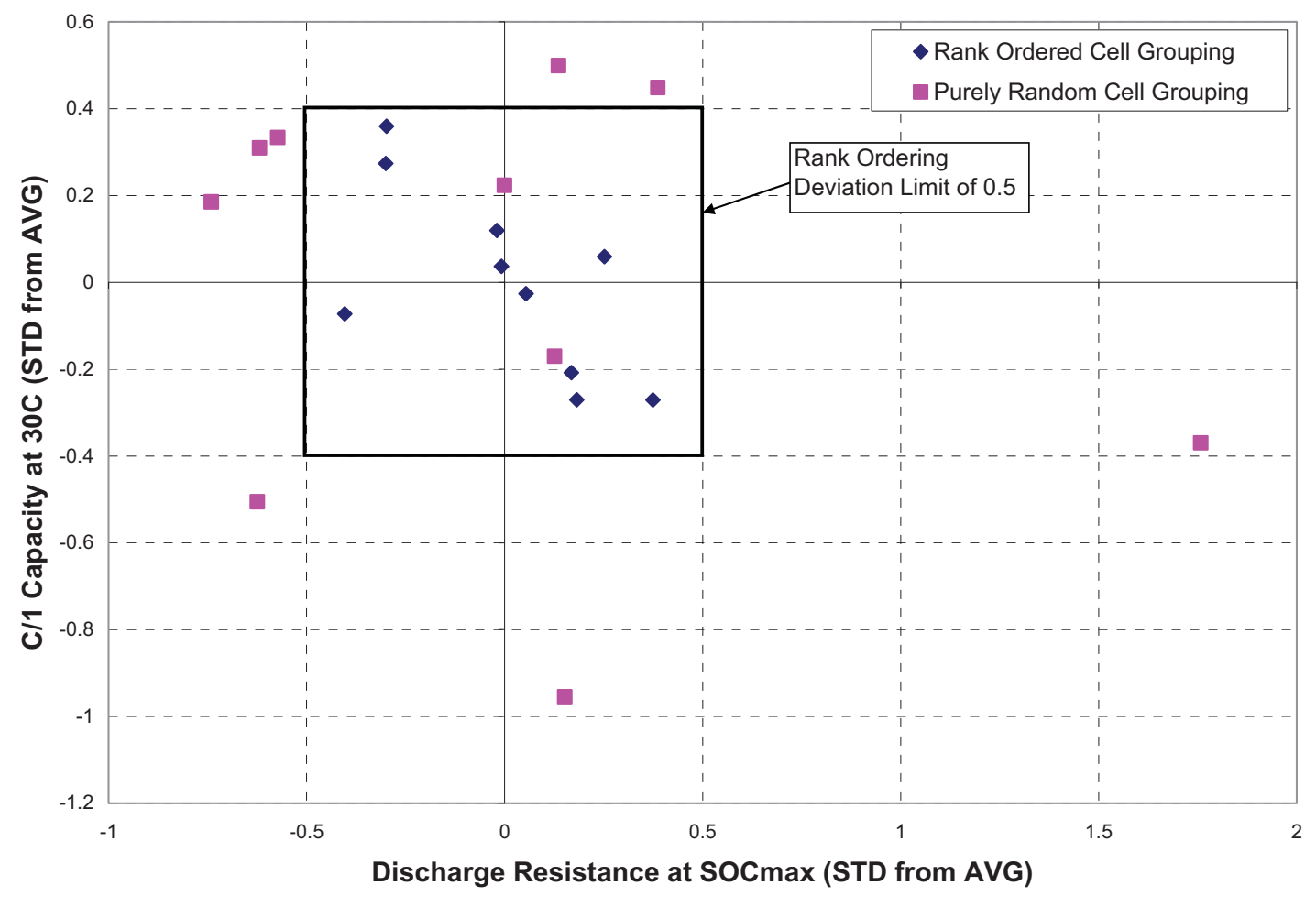

Figure 6. Sample rank ordering of cells with a deviation limit of 0.5

\subsubsection{AC Impedance Measurements}

If $\mathrm{AC}$ impedance measurements are performed, examine the spectra for anomalous characteristics, primarily in the form of cells whose behavior differs greatly from the average of the test population. This can be done by determining the equivalent series resistance (ESR) and/or the ionic impedance of each cell and plotting these characteristics versus the calculated pulse resistance at the SOC value used for the impedance testing. (Some information on the interpretation of impedance spectra results is found in Appendix C of Reference 6 and in Reference 14).

\subsection{Core Life Test Results}

Assessment of the acquired core life test data should be based on the appropriate USABC manuals (References 3 through 6). At minimal levels, the core life matrix will facilitate assessment of the main effects (and limited interactions) of the controlled factors on the responses of interest. The more comprehensive test matrices will facilitate assessment of additional interactive effects of the controlled factors on the responses of interest. In all cases it is desirable to first perform some sort of graphical analysis (e.g., main effects and interaction plots). The graphical analysis might motivate an inferential/predictive analysis such as analysis of variance (ANOVA) or response surface modeling (see e.g., Reference 15). 


\subsection{Supplemental Life Test Results}

The supplemental life test data are used to test hypotheses based on differences in the measured performance degradation parameters between samples from different groups of cells. The general procedure for this statistical analysis is summarized below, followed by summaries of how this procedure would be applied in the three candidate supplemental life tests.

\subsubsection{Hypothesis Testing}

Hypothesis testing associated with the supplemental life test matrix may be done using the general t-statistic, based on small samples, for the difference between two means as shown in Equation (6), where $\bar{X}_{1}, \bar{X}_{2}$ are the estimated means of a degradation parameter for each of two groups of cells; $S_{1}, S_{2}$ are the standard deviations of the data for each of the two groups; and $n_{1}, n_{2}$ are the number of cells for each of the two groups.

$$
t=\frac{\bar{X}_{1}-\bar{X}_{2}}{\sqrt{\left(n_{1}-1\right) \cdot S_{1}^{2}+\left(n_{2}-1\right) \cdot S_{2}^{2}}} \cdot \sqrt{\frac{n_{1} \cdot n_{2} \cdot\left(n_{1}+n_{2}-2\right)}{n_{1}+n_{2}}}
$$

The hypothesis to be tested is that there is no underlying difference in mean performance between the two groups (i.e., $\mu_{1}=\mu_{2}$, where $\mu_{1}$ and $\mu_{2}$ are the population averages associated with the two groups that are sampled). The estimated means, $\bar{X}_{1}$ and $\bar{X}_{2}$, are sample estimates of $\mu_{1}$ and $\mu_{2}$. There are three possible corresponding alternate hypotheses, the first two are one-sided alternates; the last alternate is two-sided:

- $\mu_{1}-\mu_{2}<0$

- $\mu_{1}-\mu_{2}>0$

- $\quad \mu_{1}-\mu_{2} \neq 0$

A level of significance, $\alpha$, must be specified before the hypothesis test. For the purposes of this manual, a value of 0.05 is suggested for $\alpha$. Then, the corresponding criteria for rejection of the null hypothesis in favor of one of the alternate hypotheses are as follows:

- $t<-T_{\alpha}$

- $t>T_{\alpha}$

- $|t|>T_{\alpha / 2}$

Values of $T_{\alpha}$ and $T_{\alpha / 2}$ are available from standard tables for the t-distribution with varying degrees of freedom, $v$. In general, for these tests $v=n_{1}+n_{2}-2$. 


\subsubsection{Path Dependence Studies}

There should usually be four groups of cells that must be analyzed to assess the effect of path dependence on the degradation parameters. Two groups are from the core matrix, with only one stress factor varying per group (e.g., same temperature and SOC, but one group is calendar-life aged and the other is cycle-life aged). The corresponding two groups in the supplemental life test matrix use the same test conditions as the core matrix groups, but with a switchover from one test condition to the other at a specified amount of degradation.

An example of the expected area-specific impedance (ASI) time histories for the two supplemental matrix groups is shown in Figure 7. The dashed histories show the ASI growth for the core matrix conditions, while the solid histories show the ASI growth for the supplemental matrix conditions with the switchover from one condition to the other occurring at a pre-specified ASI of $34.7 \Omega-\mathrm{cm}^{2}$. It is apparent that the ASI rates of change for the two supplemental groups of cells are shifted at the switchover point. The two hypotheses to be considered are whether the shifted ASI rates of change are equal to the rates of change of the corresponding groups in the core matrix at the same ASI values.

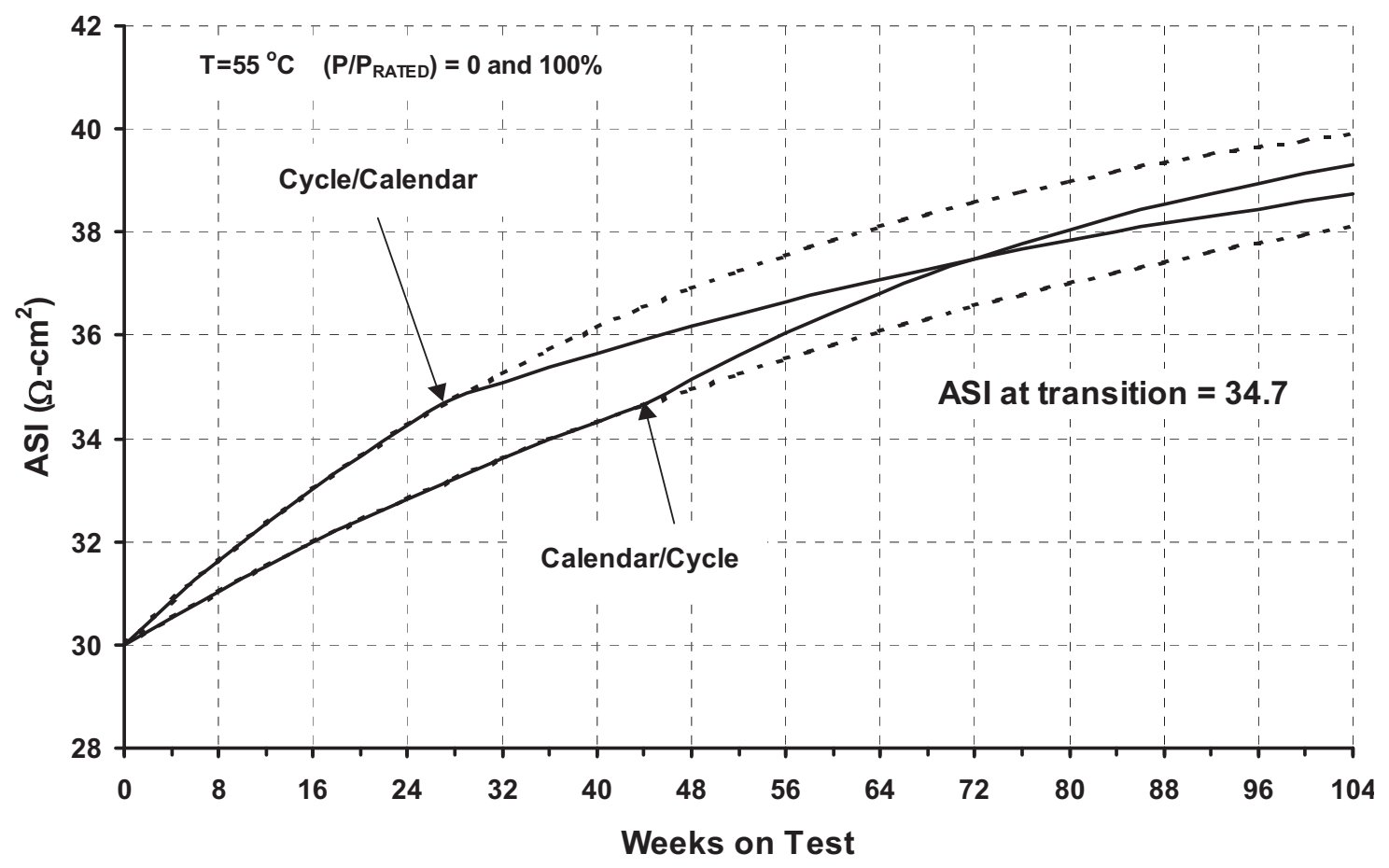

Figure 7. Expected ASI histories for combined cycle/calendar and calendar/cycle test conditions

Define the four groups of cells as follows:

- Core $_{1}=$ group of $m_{l}$ calendar life cells in the core matrix at the specified temperature 
- Core $_{2}=$ group of $m_{2}$ cycle life cells in the core matrix at the specified temperature

- Combined $_{1}=$ group of $n_{1}$ cycle/calendar life cells in the combined matrix at the specified temperature

- Combined $_{2}=$ group of $n_{2}$ calendar/cycle life cells in the combined matrix at the specified temperature

The four groups are analyzed to estimate the average ASI rates of change from the switchover ASI value to the end of the test. Due to noise in the ASI data, there will be uncertainty in the estimated rates of change. The test statistics to be used are shown in Equation (7), where $\bar{Y}_{i}$ is the average ASI rate of change associated with the $i^{\text {th }}$ Combined group of cells; $S_{i}$ is the standard deviation of ASI rate of change associated with the $i^{\text {th }}$ Combined group of cells; $\bar{X}_{i}$ is the average ASI rate of change associated with the $i^{\text {th }}$ Core group of cells; $R_{i}$ is the standard deviation of ASI rate of change associated with the $i^{\text {th }}$ Core group of cells; and $i=1,2, \ldots$.

$$
t_{i}=\frac{\bar{Y}_{i}-\bar{X}_{i}}{\sqrt{\left(m_{i}-1\right) \cdot R_{i}^{2}+\left(n_{i}-1\right) \cdot S_{i}^{2}}} \cdot \sqrt{\frac{m_{i} \cdot n_{i} \cdot\left(m_{i}+n_{i}-2\right)}{m_{i}+n_{i}}}
$$

In general, these statistics are used to assess whether or not the future ASI rate of change, beginning at a fixed/elevated ASI level, depends on how a cell has been previously been degraded to that fixed ASI level. The first t-statistic $\left(t_{1}\right)$ is used to assess whether or not the rate of calendar life degradation is affected unexpectedly by previous exposure to cycle life aging. The second t-statistic $\left(t_{2}\right)$ is used to assess whether or not the rate of cycle life degradation is affected unexpectedly by previous exposure to calendar life aging.

For example, if $\left|t_{1}\right|>T_{0.025}$ with $\left(m_{1}+n_{1}-2\right)$ degrees of freedom, it can be concluded that future calendar life aging (measured by the ASI level) depends on not just the current ASI level and future calendar life stresses, but also the nature of the previous aging (calendar life versus cycle life). Alternately, if $\left|t_{1}\right|<T_{0.025}$, then the hypothesis that future calendar life aging depends only on the current ASI level and future calendar life stresses would not be rejected. If both $\left|t_{1}\right|<T_{0.025}$ and $\left|t_{2}\right|<T_{0.025}$, then there would be insufficient evidence to reject the hypothesis that future cell aging depends only on the current ASI level and future stresses (i.e. path independence).

\subsubsection{Cold-start Verification Tests}

To verify that cold starts do not significantly affect battery life, the estimated lives on test for two of the core life test conditions will be compared with those for two supplemental groups of cells tested under the same conditions, but with the addition of a cold start test conducted as part of every periodic reference performance test. The underlying hypothesis is that $\left(L_{\text {TEST }}\right)_{\text {COLD-START }}=\left(L_{\text {TEST }}\right)_{\text {CORE }}$. The alternate hypothesis is that 


\section{$\left(L_{\text {TEST }}\right)_{\text {COLD-START }}<\left(L_{\text {TEST }}\right)_{\text {CORE }}$.}

Instead of a t-statistic, a standardized normal Z-statistic can be used for each of the two comparisons. The Z-statistics will be based on the estimated mean lives on test ( $\bar{X}_{\text {COLD-START }}$ and $\bar{X}_{\text {CORE }}$ ) and the corresponding bootstrap standard errors of the estimates $\left(S_{C O L D-S T A R T}\right.$ and $\left.S_{C O R E}\right)$ as shown in Equation (8). The criterion for rejecting the null hypothesis is then $Z_{C O L D-S T A R T}<-1.65$.

$$
Z_{C O L D-S T A R T}=\frac{\bar{X}_{C O L D-S T A R T}-\bar{X}_{C O R E}}{\sqrt{S_{C O L D-S T A R T}^{2}+\cdot S_{C O R E}^{2}}}
$$

\subsubsection{Low-temperature Operation Tests}

For the supplemental life tests involving low-temperature operation, it may be very difficult to reliably estimate life on test due to limited cell degradation within a relatively short test duration. Hence, it would be inappropriate to base a statistical test on such estimates. Instead, the average ASI rates of change over the full test duration will be used to evaluate the test statistic. Even then, the uncertainties in these rates will be relatively high, since there will be little ASI change if the tests are successful. Two groups of cells are considered. The first group $(T=L I M I T)$ represents very low temperature operation. In the second group ( $T>L I M I T)$, the operating temperature is still low but close enough to standard test conditions so as to expect no significant ASI growth. If the first group of cells operating at the limits of the performance constraints ( $T=L I M I T)$ exhibit any significant ASI growth, it should be possible to differentiate the performance of the two groups and hence identify a degrading low temperature effect. The statistical test described in Section 4.3.1 will be used to determine if low-temperature operation affects battery life, without necessarily quantifying the magnitude of the effect from these test results. Here, the underlying hypothesis is that the rate of ASI change over the two conditions is the same, as shown in Equation (9). The alternate hypothesis is shown in Equation (10) and the corresponding statistic to be used in this case is shown

in Equation (11), where $\bar{X}_{T>L I M I T}$ and $\bar{X}_{T=L I M I T}$ denote the observed average ASI change for the two groups consisting of $n_{1}$ and $n_{2}$ cells, respectively; $S_{T>\text { LIMIT }}$ and $S_{T=L I M I T}$ denote the standard deviation of the ASI change for the two groups. In the case of 8 cells per group, the criterion for rejecting the null hypothesis is $t_{L O W-T E M P}>t_{0.05}(14$ degrees of freedom).

$$
\begin{aligned}
& A \dot{S} I_{T=L I M I T}=A \dot{S} I_{T>L I M I T} \\
& \dot{A S I_{T=L I M I T}>} \dot{A S I_{T>L I M I T}}
\end{aligned}
$$




$$
t_{\text {LOW-TEMP }}=\frac{\bar{X}_{T>\text { LIMIT }}-\bar{X}_{T=\text { LIMIT }}}{\sqrt{\left(n_{1}-1\right) \cdot S_{T>\text { LIMIT }}^{2}+\left(n_{2}-1\right) \cdot S_{T=L I M I T}^{2}}} \cdot \sqrt{\frac{n_{1} \cdot n_{2} \cdot\left(n_{1}+n_{2}-2\right)}{n_{1}+n_{2}}}
$$




\section{REFERENCES}

1. Battery Technology Life Verification Test Manual, INEEL/EXT-04-01986, February 2005.

2. Battery Calendar Life Estimator Manual, Revision 1, INL/EXT-08-15136, October 2012.

3. Battery Test Manual for Plug-In Hybrid Electric Vehicles, Revision 2, INL/EXT-0712536, December 2010.

4. FreedomCAR Battery Test Manual for Power-Assist Hybrid Electric Vehicles, DOE/ID-11069, 2003.

5. USABC Electric Vehicle Battery Test Procedures Manual, Revision 2, DOE/ID10479, January 1996.

6. FreedomCAR Ultracapacitor Test Manual, DOE/NE-ID-11173, September 2004.

7. J. P. Christophersen, J. L. Morrison, W. H. Morrison and C. G. Motloch, "Rapid Impedance Spectrum Measurements for State-of-Health Assessment of Energy Storage Devices," SAE Int. J. Passeng. Cars - Electron. Electr. Syst. 5(1) (2012).

8. J. P. Christophersen, J. L. Morrison, D. M. Rose, W. H. Morrison and C. G. Motloch, "Crosstalk Compensation for a Rapid, Higher-Resolution Impedance Spectrum Measurement," Proceedings from the IEEE Aerospace Conference (2012.)

9. J. P. Christophersen, G. L. Hunt, C. D. Ho, and D. Howell, "Pulse resistance effects due to charging or discharging of high-power lithium-ion cells: A path dependence study," J. Power Sources, 173, 998-1005 (2007).

10. Advanced Technology Development Program for Lithium-Ion Batteries: Handbook of Diagnostic Techniques, LBID-2464, April 2003.

11. Diagnostic Examination of Generation 2 Lithium-Ion Cells and Assessment of Performance Degradation Mechanisms, ANL-05/21, July 2005.

12. E. V. Thomas, I. Bloom, J. P. Christophersen, and V. S. Battaglia, "Statistical methodology for predicting the life of lithium-ion cells via accelerated degradation testing," J. Power Sources, 184, 312-317 (2008).

13. Hedayat, A. S., Sloane, N. J. A., and Stufken, J., Orthogonal Arrays: Theory and Applications, New York: Springer-Verlag, 1999.

14. Linden, David and Reddy, T. B., eds., Handbook of Batteries, third edition, New York: McGraw-Hill, 2002.

15. Box, G.E.P, Hunter, J.S., and Hunter, W.G., Statistics for Experimenters: Design, Innovation, and Discovery, 2nd Edition, New York, Wiley, 2005. 